NBER WORKING PAPER SERIES

\title{
MONETARY DYNAMICS WITH PROPORTIONAL TRANSACTION COSTS AND \\ FIXED PAYMENT PERIODS
}

Sanford J. Grossman

Working Paper No. 1663
NATIONAL BUREAU OF ECONOMIC RESEARCH
1050 Massachusetts Avenue
Cambridge, MA 02138
Ju1y 1985

The research reported here is part of the NBER's research programs in Economic Fluctuations and Financial Markets and Monetary Economics. Any opinions expressed are those of the author and not those of the National Bureau of Economic Research. 
NBER Working Paper \#1663

July 1985

\author{
Monetary Dynamics with Proportional \\ Transaction Costs and \\ Fixed Payment Periods
}

\title{
$\underline{\text { ABSTRACT }}$
}

A general equilibrium model of an economy is presented where people hold money rather than bonds in order to economize on transaction costs. In any such model it is not optimal for individuals to instantaneously adjust their money holdings when new information arrives. The (endogenous) delayed response to new information generates a response to a new monetary policy which is quite different from that of standard flexible price models of monetary equilibrium. Though all goods markets instantaneously clear, the monetary transaction cost causes delayed responses in nominal variables to a change in monetary policy. This in turn causes real variables to respond to the new monetary policy.

The two classes of monetary policies analyzed here are price level policies and interest rate policies. Price level policies are monetary policies which in general equilibrium keep the nominal rate constant, but change the long run price level. We show that the money supply must rise gradually to its new steady level if the price level is to be raised without causing nominal interest rates to fall.

When interest rate policies are analyzed, it becomes clear that aggregate money demand at time $t$ depends on the path of interest rates, not just the instantaneous interest rate at time $t$. This is because the aggregate money holding at time $t$ is composed of the money holdings of various consumers, each of whom has a different but overlapping holding period. The staggering of money holding periods is a necessary condition for general equilibrium; general equilibrium requires that some consumers must be incrementing their cash when other consumers are decrementing their cash via spending. Some results of our analysis include the fact that high irequency movements of the interest rate cause a much smaller change in money demand than low frequency movements, since it is the integral of the interest rate over a holding period which determines money demand. Further, at high frequencies, the rate of inflation is not the difference between the nominal interest rate and the rate of time preference.

Sanford J. Grossman Department of Economics Dickinson Hall Princeton University Princeton, NJ 08544 (609) 452-4000 
MAY 1985

\title{
MONETARY DYNAMICS WITH PROPORTIONAL TRANSACTION COSTS \\ AND FIXED PAYMENT PERIODS
}

\author{
by \\ SANFORD J. GROSSMAN ${ }^{*}$
}

1. INTRODUCTION

A general equilibrium model of an economy is presented where people hold money rather than bonds in order to economize on transaction costs. In any such model it is not optimal for individuals to instantaneously adjust their money holdings when new information arrives. This (endogenous) delayed response to new information generates a response to a new monetary policy which is quite different from that of standard flexible price models of monetary equilibrium. Though all goods markets instantaneously clear, the monetary transaction cost causes delayed responses in nominal variables to a change in monetary policy. This in turn causes real variables to respond to the new monetary policy.

Earlier work by Grossman and Weiss (1983), Grossman (1982), and Rotemberg (1984), have considered models of the above type where individuals hold money for an exogenously fixed amount of time - their "payment period". As in the model to be developed here, these models assume that goods can be bought only with cash. However, unlike what we will assume here, individuals can exchange bonds for cash only on the exogenously fixed "paydates" which occur at the beginning and end of their payment periods. Thus an individual's money holding period is exogenously given and insensitive to the nominal interest rate. In such models when there is an unanticipated increase in the money supply, people can be induced to hold 
the new money only by a large fall in the real rate of interest. The fall in the real rate of interest induces people to increase their real spending in the current payment period relative to future payment periods. They thus hold more cash in order to be able to purchase the goods. A crucial point is that the money holding period has a zero interest rate elasticity, and thus money demand does not increase for the reason it would in the BaumolTobin model. In the Baumol-Tobin model people are induced to hold more money because even with a fixed rate of real spending people want to exhaust their money earlier when the nominal interest rate rises.

Another aspect of the exogenously fixed money holding period is that (with a zero interest rate elasticity of money demand) expected inflation has almost no effect on the demand for money and hence on the current price level. In the model to be developed here the money holding period falls when there is expected inflation, so that the price level is sensitive to announcements of monetary policy.

The model to be developed here drops the assumption of an exogenously fixed money holding period, but retains the assumption of an exogenously fixed pay period. Though current work is underway on a model with endogenous pay-periods, the model is far simpler when there is only an endogenous money holding period. Section 2 develops a particularly simple model of the money holding period by assuming that there is a proportional transactions cost of converting bonds into money at all dates except on a paydate. - ${ }^{\prime}$ on a paydate a consumer can freely transfer between bonds and money. It is shown that an optimal policy for a consumer is to withdraw an amount of cash on his paydate which is designed to finance his spending for a period of time $\vec{t}$ which depends on the path of nominal interest rates. The 
sensitivity of $\bar{t}$ to interest rates yields qualitatively and quantitatively different dynamic responses to the unanticipated monetary policy announcements, than occurs in the previously mentioned work where $\bar{t}$ is exogenously fixed.

Section 3 develops the general equilibrium for the steady state cross sectional distribution of cash. It re-emphasizes the need for a cross sectional distribution of cash with the property that the money flowing out of consumer's hands from their spending must equal the rate at which other consumers desire to increment their cash balances.

Section 4 considers the effects of unanticipated monetary policies as a perturbation of the steady state in a perfect foresight model. It is shown how the perfect foresight model can be thought of as an approximation to a rational expectations model. This Section studies unanticipated monetary policies called "price level policies", which have the effect of keeping nominal interest rates unchanged but change the path of money and the price level. For example, it is shown that there is a unique path of money which raises the price level in the long run by $\alpha$ without changing the nominal interest rate. This money supply path involves a gradual $r$ ise in money over a pay period until the money supply $r$ ises by $\alpha$. This should be contrasted with the standard flexible price LM model where the initial money supply can simply be chosen to be $\alpha$ higher, and this will immediately raise prices by $\alpha \%$. In our model if the money supply grows too rapidly, then the nominal rate is driven down, because of a "liquidity effect" associated with it being costly for consumers to increment their cash balances. In the standard LM model (say derived from Sidrauski's (1967) equilibrium model), 
it is as if all consumers can, without paying a transactions cost, increment their cash balances at any instant of their choosing.

Section 5 considers a class of monetary policies, called "interest rate policies" where the money supply is chosen to cause a particular path of interest rates to be the market clearing rates. The first interest rate paths to be considered involve a permanent $r$ ise in the nominal interest rate. Because of the liquidity effect mentioned earlier, this is associated with an initial contraction in the money supply followed by a rise in the money supply to its new steady state growth rate. Again, this differs from what would occur in the standard LM model where a rise in the nominal rate of say $1 \%$ is implemented by a new monetary growth rate of $1 \%$ (with a degree of freedom involving the level of the money supply). We go on to consider temporary interest rate changes, as well as analyzing the response of the economy to various frequencies of interest rate movements. Section 6 contains conclusions.

\section{The Consumer's Optimization Problem}

A consumer at time 0 chooses a path of consumption, money and bond holdings. At that time he has perfect foresight about the path of prices and interest rates at all times $t>0$. Bonds pay an endogenously determined rate of interest, while money earns no nominal interest. The consumer holds money because goods can only be purchased with money. The consumer can transfer between bonds and money according to the following transactions technology : At the end of each interval of length $h$ (which represents the exogenously given "pay period"), a consumer has a "pay date." At that date he can freely convert his assets between bonds and cash. At dates other 
than "pay dates" the consumer bears a transactions cost which is proportional to the amount of bonds converted to cash. He has a continuous time optimization problem which involves the choice of a time path of consumption, bonds and money to maximize lifetime discounted utility. subject to a wealth constraint and the above transactions technology.

It will be shown that the above assumptions imply that a consumer will withdraw a stock of cash $M$ on his pay date $z$, and will spend only out of cash for an amount of time $t(z)$ which depends on the path of interest rates between $z$ and (his next pay date) $z+h$. In the time remaining between $t(z)$ and $z+h$, the consumer will convert his bonds to money continuously to finance his consumption. That is, the consumer holds no (stock of) money for times $t$ satisfying $t \varepsilon[t(z), z+h]$.

The above transactions cost assumptions generate a demand for money in which the velocity of money is a function of the path of interest rates. The model will be useful for analyzing the dynamics associated with a change in monetary policy because all consumers will not find it optimal to change their cash holdings in the same proportion. Consumers who, at a given moment of time have more money, will react sonewhat less than consumers who have no money at the time of the unanticipated change in policy. $1 /$

Assume that at each date there is a single consumption good. Let $P(t)$ be the money price of the good at date $t$. Let $Y(t)$ be the value at date $t$ of 1 dollar invested at time 0 . Thus $\frac{\dot{Y}(t)}{\gamma(t)}=r(t)$ is the interest rate at time $t$. Let $M_{0}$, and $W_{0}$ denote the money holding and nominal wealth of the consumer at time 0 . Let $m(t)$ denote the flow value of bonds sold at $t$ ime $t$, and let $(\mathrm{k}-1)>0$ denote the transactions cost per dollar of bonds converted 
into cash. Finally let $M(t)$ be the stock of money held at $t$. Throughout the paper we will use the notation $x_{+}=\operatorname{Max}(0, x)$. Consider a consumer whose last paydate was at time $z \varepsilon(-n, 0)$. His optimization problem involves maximizing

(2.1)

$$
\sum_{n=0}^{\infty} \int_{(z+n h)}^{z+(n+1) h} u(c(t)) e^{-\beta t} d t
$$

subject to:

(2.2a) $\quad \int_{0}^{z+h} \frac{k m(t)}{\gamma(t)} d t+\sum_{n=1}^{\infty}\left[\int_{z+n h}^{z+(n+1) h} \frac{k m(t)}{\gamma(t)} d t+\frac{M^{+}(z+n h)}{\gamma(z+n h)}\right]$

$$
\leq W_{0}+\frac{M^{-}(z+h)}{Y(z+h)}+\frac{D_{0}}{k}
$$

(2.2b) $M(t) \geq 0$;

(2.2c) $m(t) \geq 0$;

(2.2d) $M(t)=m(t)-P(t) c(t) \quad t \neq z+h, z+2 h, \ldots ;$

(2.2e) $M(0)=M_{0}-D_{0} ;$

where $B \varepsilon(0,1)$ is his rate of time preference, and a superscript $l i k e M^{+}(t)$ indicates $\lim _{x+t} M(x)$ and $M^{-}(t)=\lim _{x+t} M(x)$. 
The (LHS) left hand side of $(2.2 a)$ is the present value of the consumer's spending out of bonds and money. There is a stock withdrawal of $\mathrm{M}^{+}(z+\mathrm{nh})$ at the $\mathrm{n}^{\text {th }}$ paydate which bears no transactions cost, and flow withdrawals $m(t)$ at $t$, which cost $\mathrm{km}(t)$ due to the transactions cost of converting bonds to money. The (RHS) right hand side of (2.2a) involves the term $\vec{M}(z+h)$ because the consumer may decide not to exhaust his initial stock of money $(M(0))$ by the time of his first paydate $z+h$. we permit the consumer to make a stock deposit in his bank account of $D_{0} \geq 0$ at time 0 out of his initial cash holding $M_{0}$, as indicated in (2.2e). The transactions cost of $D_{0}$ is such that wealth increments by only $D_{0} / k$ in (2.2a).

The wealth constraint assumes that any money withdrawn on a paydate $z+$ nh $>0$ will be totally spent by the next paydate. There is no loss of generality in this assumption because if $r(t)>0$, as we shall assume throughout, it is obviously never optimal for a consumer to withdraw more money than he will spend before his next paydate. However, since the economy faces a monetary policy which at time 0 is different than was anticipated at the last paydate $z<0, M_{0}$ may not be the money which would have been desired at $t=0$ under the new policy. Therefore $M^{-}(z+n)$ need not be zero and $D_{0}$ may be non-zero.

Inequality (2.2b) is the condition that consumers cannot create cash. Inequality (2.2c) requires that the consumer cannot make flow deposits into his bank account. This constraint is here for notational simplicity only. The transaction cost of depositing a dollar at a date which is not a paydate is such that the bank account only increase by $i / k$ dollars, If $r(t)>0$, as we shall assume throughout, the consumer will only want to make a deposit, at most in the interval $t \varepsilon[0, z+h]$, since at all future dates he can choose 
his money stock withdrawn so that a deposit is never necessary. Similarly for the given stock $M_{0}$ at $t=0$, a consumer who desired to make a deposit during $t \varepsilon(0, z+h)$, will always find it optimal to make the deposit at $t=0$ instead, and this is captured by $D_{0}$.

Equation (2.2d) is the accounting identity that the consumers stock of cash falls at the rate of his spending when $m(t)=0$, and otherwise is incremented by his bond withdrawals.

The maximization of $(2.1)$ is accomplished by the controls $c(t), m(t)$ and $D_{0}$ subject to $(2.2)$ with $W_{0}$ and $M_{0}$ given. We assume that $u(\cdot)$ is concave, and it is easy to verify that this optimization problem involves $a$ concave objective and a convex constraint set. $\underline{2}$ Further, it is easy to verify that

(2.3) $M(t)>0$ implies $m(t)=0$.

Fact (2.3) holds because with $r(t)>0$, if both $M(t)>0$ and $m(t)>0$, then the consumer can keep $c(t)$ unchanged, set $m(t)=0$ until $M$ reaches zero and then finance consumption out of $m$. This increases wealth because interest is earned over the period in which the withdrawal is delayed.

Since the consumer does not make withdrawals until his moeny is exhausted, it is possible to simplify the problem by defining the controls $t_{n}$ which specify the time in the $n^{\text {th }}$ pay period when the consumer decides to exhaust his money holdings. Hence (2.1) and (2.2) are equivalent to maximizing 
$(2.4)$

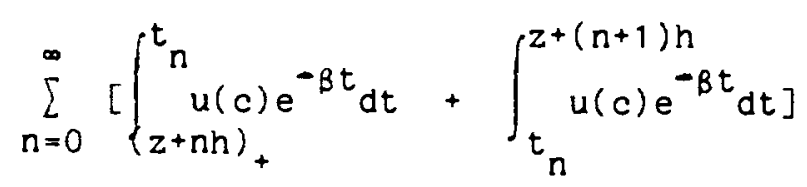

subject to

$$
\sum_{n=0}^{\infty}\left[\int_{t_{n}}^{z+(n+1) h} k \frac{P(t) c(t)}{\gamma(t)} d t+\frac{1}{\gamma(z+(n+1) h)} \int_{z+(n+1) n}^{t} P(t) c(t) d t\right] \leq
$$

$$
\text { Wo }+\frac{1}{\gamma(z+h)}\left[M_{0}-D_{0}-\int_{0}^{z+h} P(t) c(t) d t\right]^{+}+\frac{D_{0}}{k}
$$

$(2.5 b) \quad \int_{0}^{t_{0}} P(t) c(t) d t \leq M_{0}-D_{0}$

where the maximization is with respect to the controls $\left\{t_{n}\right\}_{n}^{\infty}=0$ and the path of $c(t)$ with the obvious nonnegativity constraints: $c(t) \geq 0$ and $t_{n+1}-$ $t_{n} \geq 0, t_{n} \in[(z+n h)+z+(n+1) h]$

Appendix A gives necessary and sufficient conditions for the maximization of $(2.4)$. One important condition is that if $T(x)$ denote the solution to

(2.6) $\quad \frac{\gamma(T)}{\gamma(x)}=k$

for $T$ as a function of $x$, then

(2.7) $\quad t_{n}=\min [z+(n+1) h, T(z+n h)]$ for $n \geq 1$. 
This follows from the observation that if a consumer is exhausting his money holdings at $t_{n}<z+(n+1) h$, then if he withdraws $1 \$$ more at $t i m e z+n h$, this costs $1 / \gamma(z+n h)$, while the benefit is that he can save the conversion of bonds into money to finance $h$ is consumption, $i . e .$, save $k / \gamma\left(t_{n}\right)$ per dollar of consumption. Thus ignoring the boundary possibility, if the interest rate is $r$, the money holding period $T-x$ implied by $(2.6)$ is

(2.8) $\quad T-x=\frac{\operatorname{lnk}}{r}=\frac{k-1}{r}$

So a transaction cost of $1 \%$ and an interest rate of $10 \%$ per year would imply an exhaustion interval of $1 / 10$ of a year.

The optimal consumption path for $y \geq t_{0}$ must satisfy

(2.9) $\quad e^{-B y} u^{\prime}(c(y))=k \frac{P(y) q}{\gamma(y)}$ for $t_{n} \leq y<z+(n+1) h n=0,1,2,3, \ldots$;

(2.10) $\quad e^{-B y} u^{\prime}(c(y))=\frac{P(y) q}{Y(z+n h)}$ for $z+n h \leq y<t_{n} n=1,2,3 \ldots$;

where $q$ is the Lagrange multiplier for (2.5a), the interpretation of (2.9) is that the cost of $c(y)$ when it is financed out of bonds is $k P(y)$, while the RHS of $(2.10)$ gives the cost of $c(t)$ out of money during the $n^{\text {th }}$ pay period as $P(y) / \gamma(z+n h)$.

The choice of $t_{0}$ is much more complicated because the initial money $M_{0}$ is based upon a withdrawal at time $z<0$ before the monetary policy is announced. The optimal choice is characterized in the Appendix, but for the moment we will be concerned with the special case where $D_{0}=0$ and the 
consumer always chooses to exhaust his money before $z+h$. This will indeed be the case if the monetary policy is inflationary relative to what was expected. The numerical simulations for deflationary policies use the appropriate formulae from the Appendix.

It is useful to define $c(t, y)$ as the solution to

(2.11) $\quad u^{\prime}(c) e^{-\beta t}=y P(t)$

for $c$ as a function of $t$ and $y$. Under the assumption of exhaustion by $z+n$ :

(2.12) $\quad M_{0}=\int_{0}^{t_{0}} P(t) c(t) d t$.

Using (A5) in the Appendix, there exists $\lambda \geq 0$ which is the Lagrange Multiplier for $(2.12)$ ) such that

(2.13) $\quad M_{0}=\int_{0}^{t_{0}} P(t) c(t, \lambda) d t$

(2.14) $\quad r\left(t_{0}\right) \lambda=q k$

Given the marginal utility of wealth $q,(2.13)$ and (2.14) jointly determine $t_{0}$ and $\lambda$. The interpretation of (2.14) is straightforward: $\lambda$ is the marginal utility of cash at time 0 , so a reduction in the exhaust time $t_{0}$ generates cash worth $\lambda$ at time 0 in utility, but costs $q k / \gamma\left(t_{0}\right)$ in the 
utility of wealth foregone from the transactions cost of maintaining consumption when money runs out.

The Logarithmic Utility Case

In the case of jogarithmic utility, i.e., where $u(c)=10 g \mathrm{c}$, the optimal $c(t)$ and $M(t)$ can be computed. Let $M(t, z)$ denote the money holdings at $t$ of someone whose last paydate before time 0 was at $z$, henceforth called Mr. z. Similarly, let $S(t, z)$ represent consumer $z$ 's gross spending; given by $P(t) c(t)$ when ne spends out of money, and $k P(t) c(t)$ when he spends out of bonds. Further let $t_{n}(z)$ represent the $t_{n}$ in $(2.7)$ and $t_{0}(z)$ represent the solution to (2.13) and (2.14) for Mr. z. Then using (2.6), (2.7) and the fact that all money withdrawn at $z+n h$ is spent by $t_{n}$ :

(2.15) $M(t, z)=\left\{\begin{array}{l}\frac{\gamma\left(t_{n}(z)\right)}{k q} \frac{e^{-\beta t}-e^{-\beta t_{n}}(z)}{\beta} \text { for }(z+n h)_{+} \leq t \leq t_{n}(z) \\ 0 \text { for } t_{n}(z) \leq t<z+(n+1) h\end{array}\right.$

(2.16) $S(t, z)=\left\{\begin{array}{l}\frac{\gamma(t) e^{-\beta t}}{q} \text { for } t_{n}(z) \leq t<z+(n+1) n \\ \left.\frac{\gamma\left(t_{n}(z)\right) e^{-\beta t}}{k q} \text { for }(z+n n)_{+} \leq t<t_{n}(z) . \underline{3}\right)\end{array}\right.$

Eq. (2.13) can be used to show that

(2.17) $\lambda(z)=\frac{1-e^{-\beta t_{0}(z)}}{\beta M_{0}(z)}$,

where $M_{0}(z) \equiv M(0, z)$, and $\lambda(z)$ is the multiplier for a person with paydate z. Substituting $(2.17)$ into $(2.14)$ yields 
$(2.18) \quad k=\frac{1-e^{-\beta t_{0}(z)}}{q B M_{0}(z)} \gamma\left(t_{0}(z)\right)$.

Substituting $(2.15)$ and $(2.16)$ into $(2.5 a)$, and maintaining the assumption that $D_{0}=0$ and $t_{0}<z+h$, we get

(2.19) $\quad q=\frac{e^{-\beta t_{0}(z)}}{B W_{0}}$

Note that given interest rates $Y(\cdot)$, and $w_{0}$ and $M_{0}$ for $M r, z,(2.18$ ) and (2.19) can be used to solve for $t_{0}(z) ;(2.7)$ gives $t_{n}(z)$ for $n \geqq 1$; and (2.15) and (2.16) are then used to solve for $M(t, z)$ and $S(t, z)$.

\section{General Equilibrium and the Steady State}

In the previous section we took as given consumer $z$ 's paydates, his time zero wealth $W_{0}(z)$ and his time zero money stock $M_{0}(z)$. In order to describe the general equilibrium more fully it is necessary to specify the cross sectional distribution of these characteristics at time zero. First note that by "general equilibrium" we mean a path of prices $P(t)$, money supply $Y^{s}(t)$, and interest factors $\gamma(t)$ such that the goods, money, and bond markets clear. By a "steady state," we mean a time independent cross sectional distribution of real balances such that $r(t)$ and $\dot{P}(t) / P(t)$ are independent of time. It is shown in Appendix $B$ that the only cross sectional distribution of paydates consistent with such a steady state equilibrium is a uniform distribution. 
We will take the consumer's paydates as exogenously given and thus unchanged when the economy is surprised at time 0 by the new monetary policy. Clearly, if there is a fixed transactions cost of adjusting the paydates, then there will be a range of shocks for which this will be a reasonable approximation. However, this is not studied here.

We shall assume throughout that monetary policy is conducted by open market operations and not by direct transfers to consumers. This is a crucial assumption; if newly issued money is hand delivered to all consumers then the liquidity effects and monetary non-neutralities which we will analyze will not appear. We shall assume that aggregate real wealth involves a claim to the exogenously given output of "stores" which produce a flow of real output $Y(t)$. As in Grossman-Weiss [1983] we will assume that there are no non-neutralities associated with the tax burden of the government debt retired when an open market operation occurs, i.e., the interest on the debt is paid by lump sum taxes levied on all (infinitely long lived) consumers. This implies that when a monetary injection occurs via an open market operation at time $t$, then aggregate consumer nominal wealth is perceived to rise by $\dot{M}^{s}(t)$ (since taxes will not have to be paid to finance interest on the debt and an open market operation reimburses directly holders of the debt for the capital value of the bond which they sel1). Hence aggregate nominal wealth at time 0 is

(3.1) $\quad W_{0}=\int_{0}^{\infty}\left[\frac{P(t) Y(t)+\dot{M}^{3}(t)}{Y(t)}\right] d t$. 
We assume that each consumer $z$ owns part of $W_{0}$ given by $W_{0}(z)$, which satisfies:

(3.2) $w_{0}=\frac{1}{h} \int_{-h}^{0} w_{0}(z) d z$.

where the first paydates $z$ are assumed to be uniformly distributed on [$h, 0]$, where $h$ is the exogenously given time between paydates.

In Grossman and Weiss [1983] we considered an economy where the only assets held by individuals were bonds, money, and claims to profit flows from the stores. Consumers also faced tax liabilities associated with the levies needed for interest payments on government bonds. Steady states were considered in which consumers had assets and tax liabilites in such a way that they would all choose identical consumption profiles irrespective of what date they have a paydate, i.e., a person's consumption depended only on how much time has elapsed since his last paydate. Here we will consider a generalization of this hypothesis. We shall assume that the cross sectional distribution of initial wealth (i.e., assets net of liabilities) is such that all consumers have the same marginal utility of wealth, denoted by $q$ in the last Section. This assumption, which is discussed further in Section 4 , is made to avoid having to analyze the effects of an open market operation on the cross sectional distribution of wealth, and any consequential effects on prices and interest rates. It can be imagined that before consumers know the paydate they will be assigned, they are ex-ante identical and are capable of trading securities which are equivalent to state-contingent claims which pay, say $\$ 1$, into the bank account of the consumer, as a 
function of the paydate which he will ex-post be assigned. The effect of this insurance will be to equalize all the consumers' marginal utility of wealth.

With the above remarks in mind, we can define a general equilibrium as a marginal utility of wealth $q$, path of prices $P(t)$, interest factors $Y(t)$, and money supply $M^{S}(t)$ such that

$$
\begin{aligned}
& \text { (3.3) } \frac{1}{h} \int_{-h}^{0} M(t, z) d z=M^{s}(t) \\
& \text { (3.4) } \frac{1}{h} \int_{-h}^{0} S(t, z) d z=P(t) Y(t)
\end{aligned}
$$

where the initial cross sectional distribution of money and the path of output are taken as given. Note that we do not specify the initial cross sectional distribution of wealth, $W_{0}(z)$. Given a marginal utility of wealth $q$, equalized across agents, and the cross sectional distribution of money $M_{0}(z)$, the demand functions for money and spending $M(t, z ; q)$, $S(t, z ; q)$ are well defined. A variant of Walras Law can be used to show that if (3.3) and (3.4) are satisfied for these functions then the present value of spending ( $1 . e$. , the LHS of $(2.2 a)$ ), when integrated over all consumers equals $W_{0}$. Thus for every $q$, there exists a cross sectional distribution of wealth $W_{0}(z)$ such that the posited prices clear markets for that wealth distribution.

In the steady state with $r(t) \equiv r$, the holding period for money is given by $(2.6)$ and $(2.7)$ as 
(3.5) $\quad \bar{t} \equiv t_{n}-[z+n h]=\operatorname{Min}\left[n, \frac{\log (k)}{r}\right]$.

In order to compute the cross sectional distribution of money we can use the equations derived for optimal consumption and money holdings in Section 2. In particular, consider calendar time $t>t$, the only people holding money are those who have had a paydate in $(t-\bar{t}, t)$. Hence if we define the inverse of $u(\cdot)$ by

(3.6) $V(y) \equiv\left[u^{\prime}\right]^{-1}(y)$

and use (2.10), then if Mr. $x^{\prime} s$ paydate satisifies $x \varepsilon(t-\vec{t}, t)$

(3.7) $M(t, x)=\int_{t}^{x+\tilde{t}} P(y) V\left(e^{\beta y} P(y) e^{-r x} q\right) d y$.

Therefore by (3.3) aggregate money at $t$ must satisfy

(3.8) $M^{s}(t)=\frac{1}{h} \int_{t-t}^{t} M(t, x) d x$,

when it is recalled that by time $t$, the people with paydates in $[t-h, t-\vec{t}]$ have already exhausted their money and are financing their consumption out of bonds. Similarly aggregate consumption at $t$ must satisfy 
(3.9) $Y(t)=\frac{k}{h} \int_{t-h}^{t-\vec{t}} V\left(e^{B t} P(t) e^{-r t} q k\right) d x+\frac{1}{h} \int_{t-\vec{t}}^{t} V\left(e^{B t} P(t) e^{-r x} q\right) d x$

where the first term on the RHS uses (2.10) and gives the total spending at $t$ (inclusive of transactions services) by consumers who have exhausted their money balances, while the second term is the real spending of those consumers who have not exhausted their money at time $t$. Note that we are computing the symmetric steady state and thus $q$ is independent of a person's paydate.

In what follows we will assume $Y(t) \equiv Y$, and then (3.9) can easily be shown to imply that

(3.10) $B+\pi=r$

since $P(t)=P(0) e^{\pi t}$. This fact can then be used in (3.7) and (3.8) to show that $M^{3}(t)$ must be growing at rate $\pi$. Thus in a steady state we can write $(3.7)-(3.8)$ as

(3.11) $\frac{M^{s}(0)}{?(0)}=\frac{1}{h} \int_{0}^{t}\left[\int_{w}^{t} e^{\pi(\alpha-w)} V\left(e^{r \alpha} p(0) q\right) d \alpha\right] d w$

(3.12) $\quad Y=\frac{k}{h}(h-\vec{t}) V(P(0) q k)+\frac{1}{h} \int_{0}^{t} V\left(e^{r y} P(0) q\right) d y$

Thus in the steady state, with real output constant, a given money growth rate $\pi$, or equivalently an interest rate policy $r$, determines $\pi$ and $r$ from 
(3.10) and an individual's exhaustion time $t$ by (3.5); Eq. (3.12) determines the marginal utility of real wealth $P(0) q$, and $(3,11)$ determines the equilibrium level of real balances $M^{S}(0) / P(0)$.

In the case of logarithmic utility, (3.11) and (3.12) become respectively:

(3.13) $\frac{M^{s}}{P}=\left[\frac{1-e^{-r \tilde{t}}}{r}-\frac{e^{-\beta \tilde{t}}-e^{-r \tilde{t}}}{\pi}\right] \cdot \frac{1}{P(0) \mathrm{qh} B}$;

(3.14) $Y=\frac{h-\bar{t}}{h P(0) q}+\frac{1-e^{-r \bar{t}}}{h P(0) q r}$.

If $(3.14)$ is substituted into $(3.13)$ to eliminate $P(0) q$, and if the interior portion of (3.5) is used to solve for $t$ as a function of $k$ (i.e., $r \bar{t}=\log k$ ), then a second order Taylor expansion of (3.13) about $k$ $=1$ yields

(3.15) $\quad \frac{M^{s}}{P}=\frac{(k-1)^{2}}{2}\left(\frac{3 r+2 \beta}{2 r^{2}}\right) \frac{Y}{8 h}$.

Referring to (3.5) we see that if the transactions cost $k-1$ is $.25 \%$, then $t$ is one month when $r=B=3 \%$ per year. Under these parameters if $h$ is about 1.67 months, then $M^{S} / P Y$ is about $3 / 4$ of a month. That is, if each consumer chooses to hold one month's worth of his spending in money, and there is 1.67 months between paydates, then the economy will have about $3 / 4$ worth of a month's income in real balances. Note that $M^{S} / P Y$ will always be lower than $t$ because (a) consumers have spent all of their money by the 
end of $\bar{t}$ (their average cash holding is approximately $P Y \bar{t} / 2$ dollars) and (b) a fraction of consumers hold no cash. Clearly to get an aggregate money holding period of $5-8$ weeks of income, as is observed in the US, each individual in our model must have a long exhaust time. This result is an artifact of the fact that each dollar that a consumer spends at $t$ goes immediately to the bond market and is immediately withdrawn by someone with a paydate at $t$. In our economy a consumer may pay a firm or another consumer, who after some delay may pay another firm or another consumer, etc. That is, it takes some time before a dollar spent by a consumer is used to purchase bonds (i.e., returns to the bank). Thus each "consumer" in our model should be interpreted as representing all the consumers and firms who hold a given dollar between the time it is withdrawn from a bank and the time it returns to the banking system.

Eq. (3.15) can be used to compute the interest elasticity of money demand:

(3.16) $\quad n \equiv \frac{\partial \log M^{s} / P}{\partial \log r}=-\left(\frac{3 r+4 B}{3 r+2 B}\right)$.

If $B=r$ the elasticity is $-7 / 5$, while at $r=5 B(\mathrm{e.g}, \quad B=3 \%$ and $r$ $=15 \%$ ) the elasticity is -1.1 . These interest rate elasticities are substantialiy higher than is predicted by the fixed-cost Baumol-Tobin model. However, it must be recalled that (3.13) is computed under the assumption that the proportional transactions cost $k$ is sufficiently low relative to the interest rate that all consumers withdraw an amount of cash on their paydate which is insufficient to cover all their expenditures up to the next 
paydate. If instead $k$ was sufficiently large relative to the interest rate, so that all consumers set $\bar{t}=h$, i.e., they strictly prefer to withdraw cash only on paydates, then (3.13) will yield an interest elasticity which is essentially zero. A second order expansion of (3.13) with $\vec{t}=h$ will convince the reader that $M / P$ depends on $r$ through terms like $h-h^{2} r / 2$, which is suggestive of a very low interest rate elasticity. Indeed numerical evaluation of the interest rate elasticity for (3.13) yields numbers like .001 for values of $h$ equal to around one month, and values of $\beta$ and $r$ ranging from $3 \%$ to $15 \%$.

It seems reasonable that in our economy there are some agents facing a high $k$ and some facing a low $k$. In particular it may well be a good approximation to assume that some agents (e.8.. poor people) face a $k$ sufficiently large so that they never make a withdrawal between paydates. while other agents (e.g., rich people) have a small $k$ and hence make a withdrawal between paydates. Depending upon the proportions of each type the interest rate elasticity of money demand can be anywhere between zero and $n$ in (3.16). It is easy to extend the general equilibrium analysis presented here to the case where there is a fixed proportion of each type. 


\section{Liquidity Effects and Monetary Policies}

If the cross sectional distribution of money and wealth at time 0 is given by $M_{0}(z)$ and $W_{0}(z)$, then we could attempt to answer the following question: Given any new money supply path $M^{S}(t)$, for $t \geq 0$, what will be the path of prices and interest rates such that all markets clear when consumers have perfect foresight for $t>0$ ? We will instead answer this question for a particular set of money supply paths to be described below. Further, for the class of functions $M^{S}(t)$ to be analyzed, we will make a simplifying assumption regarding wealth effects. In particular, as noted earlier, the wealth effects of a shock at time 0 on the cross sectional distribution of wealth will be very sensitive to the types of assets people hold prior to time 0 . Further, for the shocks of a magnitude in which it is reasonable to keep the time between pay dates a constant, the shock's effect on the cross sectional distribution of wealth is likely to be very small. (Recall from the discussion in Grossman and Weiss [1983] that the cross sectional distribution of wealth is affected because (i) at the time of the shock some consumers are holding more of their wealth in bonds rather than money, and (ii) the tax liabilities associated with the interest payments on the bonds can be nonneutral.) For these reasons we will assume that the postshock cross sectional distribution of wealth always has the property that all consumers' have the same marginal utility of wealth at time zero, equal to say, q.

It may help the reader to understand the above assumption if the perfect foresight economy is imbedded in a rational expectations economy as follows. Imagine that monetary policy can take on two values: (a) a steady state value or (b) the path $M^{S}(t)$ which we previously called the post-shock path. Let the economy begin with the steady state money path and let the 
arrival of the postshock policy be a Poisson event with probability of occurence pdt. Further, once the new policy occurs, it is the permanent state of the economy. Let there be a complete set of state contingent bond markets in the economy. That is, a consumer can buy a promise to have $\$ 1$ delivered to his bank account at any time under any contingency. He cannot contract for the delivery of state contingent cash without paying the transactions cost described in Section 2. If all consumers are ex-ante identical, then they will trade state contingent securities to equalize their ex-post marginal utility of wealth. Ex-ante the shock, there will be a cross sectional distribution of cash which will not be identical to the one described in Section 3 because consumers will have to take account of the possibility of a change in prices and interest rates associated with the new money supply $M^{S}(t)$. However if $p$ is close to zero then the steady state cross sectional distribution of money derived in the last section will closely approximate the pre-shock cross sectional distribution which arises when consumers take account of the possibility of the shock. In any case, the qualitative results to be derived will not rely on the exact form of the pre-shock cross sectional distribution of cash.

One method of studying the dynamics associated with a new monetary policy is to posit a particular new money supply path $M^{S}(t)$, e.g., a $g$ percent increase in money growth, and then to find the $P(t), r(t)$ which clear all markets. However a simpler approach will be taken here. The policies will be characterized by their effects on the path of market clearing interest rates. The first type of policy will be a money supply path $M^{S}(t)$ which keeps the nominal interest rate unchanged, i.e., at its original steady state value. The second type of policy to be considered is one where the monetary authority picks a new interest rate path $r(t)$, and 
chooses $M^{S}(t)$ so that $r(t)$, and some $P(t)$, will clear markets. For reasons which will become clear below, we call the first type of policy a price level policy and the second type of policy an interest rate policy.

\section{Price Level Policies}

In the standard LM model of money demand, where for example, all consumers get utility out of holding real balances (as in the Sidrauski [1967] model), the only monetary policy which will keep the nominal rate constant is a once and for all change in the stock of money. That is, taking real output as fixed and the real interest rate as $f$ ixed at $B$, such models imply:

$(4.1) \frac{M}{P}=L(r)=L(B+\dot{P} / P)$

If the nominal rate is unchanged by the shock, then $\dot{P} / P$ and $M / P$ must unchanged by the shock. Hence, the rate of growth in money must be unchanged. Hence if a new monetary policy is announced at time 0 , and the new policy does not change the nominal interest rate, then it can only involve a once and for all jump in the level of money and the price level at time 0 .

In contrast to the above scenario in the standard LM model, our model does not have equilibria which involve a jump in the money supply in the presence of an unchanged, positive, nominal interest rate. For example, if $r=3$ then a monetary policy designed to raise the price level by $5 \%$ must, at first, involve a gradual growth in the level of the money supply until the stock of money is 5\% higher than its initial value. We will be able to 
prove these results because, in the model considered here, the money supply can oniy be incremented via an open market operation, and not by the direct delivery of cash into the hands of consumers. Therefore, if the government wants to zet the stock of cash up by $5 \%$, it must induce people to hold $5 \%$ more cash than they otherwise would. However, a consumer who holds a stock of cash at time 0 will not find it optimal to make a withdrawal at time 0 which increments his cash-ahe would do better to wait until his cash is exhausted. Further, consumers who hold no cash at time 0 , do not find it optimal to withdraw a stock of cash when there is a proportional transactions cost. Hence the only type of person who will increment his cash to a higher level than it would have been at is a person who has a paydate at time 0 . However, this consumer only holds an infinitesimal proportion of the economy's money stock.

In summary, we will show that the liquidity effect associated with staggered paydates implies that the only way the price level can be raised without changing (i.e., lowering) interest rates is by a gradual increase in the money supply. To see this it is useful to define

$$
t_{0}^{*}=\operatorname{Max}_{z} t_{0}(z), \tilde{t}_{0}=\operatorname{Max}\left(\tilde{t}, t_{0}^{*}\right)
$$

where $\bar{t}$ is the pre-shock money holding period $(\bar{t}$ is also the new steady state holding period if interest rates are unchanged), and $t_{0}^{*}$ gives the longest time it takes for any consumer to exhaust the cash he held at time 0 . Thus for $t>\bar{t}_{0}$ any cash held in the economy will have been withdrawn after time 0 . Note further that the exhaustion time chosen by a person at any paydate after time 0 (i.e., $t_{n}$ for $n \geq 1$ ) will be $\bar{t}$ if interest rates 
are unchanged; see eq (2.6). Next, note that when $t>\bar{t}_{0}$, the fraction of people spending out of cash stocks is equal to its steady state value of $E / h$. Therefore we may use (3.3) and (3.9) for the money and goods market clearing conditions when $t>\bar{t}_{0}$. It is clear from (3.9) that since $V^{\prime}<0$, there is a unique number $P(t) q$ which satisfies (3.9) for each $t$. Hence with $r$ fixed the only degree of freedom which the monetary authority has is to choose different values of $q$, and this changes $P(t)$ so as to keep $P(t) q$ constant. That is, the feasible changes in money supply which keep $r$ constant will be equivalent to changes in $q$. More precisely, examining (3.7) and (3.8), if $P(t) q$ is unchanged for $t>t_{0}$, then $M^{S}(t) q$ must also be constant. We can therefore think of the monetary authority as choosing $a$, and thus choosing the level of $P(t)$ and $M^{S}(t)$ for $t \geq t_{0}$.

Consider the standard LM model in which a monetary policy is chosen which keeps interest rates unchanged and causes the level of money at each time to be $\alpha \%$ higher than it otherwise would have been. Thus for $t \geq \tilde{t}_{0}$ the equilibrium caused by a price level policy in our model is identical to the equilibrium in the standard LM model. The distinction between the two models arises for $t \varepsilon\left(0, \bar{t}_{0}\right)$. During that time money will not be $\alpha:$ higher in this model, since those people who are not having a paydate will not find it optimal to increment their stock of cash. Instead $M(t)$ will gradually rise at a rate just designed to prevent the interest rate from falling. This is readily proved in this case of logarithmic utility. A useful preliminary result is to show that for a given steady state interest rate $r$, and a given $q$, there is $\exists$ unique $M^{S}(t)$ and $P(t)$ such that all markets clear, and conversely for a given $r$ and $M^{S}(t)$ there is a unique $P(t)$ and $q$ such that all markets clear. That is, as long as the monetary authority chooses a 
policy of keeping interest rates unchanged, we may discuss the policy as if it were a choice of $q$ rather than $M^{S}(t)$.

Theorem 4.1 Assume that $u(c)=10 \mathrm{~g}$. Let the economy be in a steady state with an interest rate $r$ at time 0 , when a new monetary policy is announced. If a new monetary policy keeps the interest rate at $r$, then the policy, generated by a particular $M^{3}(t)$, implies $a$ unique $P(t)$ and $q$ sucin that ail markets clear. Conversely for each choice of $q$, there is a unique $M^{S}(t)$ and $P(t)$ such that all markets clear when the interest rate is $r$.

Proof We have already shown that for $t>t_{0}, P(t)$ and $M^{3}(t)$ must each grow at the (old) steady state value of $r-\beta=\pi$, with the level of each having the property that $M^{S}(t) q$ and $P(t) q$ are unchanged when $q$ changes. Therefore $M^{S}(\cdot)$ determines a unique $q$. We now study the market clearing conditions at time $t<t_{0}$, i.e., before everyone has exhausted their pre-shock money holdings. It is useful to define $z_{0}(t)$ as the inverse function of $t_{0}(z)$, i.e. $z_{0}(t)$ is the paydate of the person who decides to exhaust his initial money at time $t$. Let $z_{0}(t)=0$ if $t>t_{0}^{*}$, and $L \equiv \operatorname{Max}(0, t-t)$. We can use $(2.9),(2.11)-(2.14)$ to write $(3.4)$, for $t<t_{0}$, as 
$\begin{aligned}(4.2) P(t) Y(t) & =\frac{1}{h} \int_{L}^{t} P(t) V\left(\frac{e^{B t} P(t) q}{Y(x)}\right) d x+\frac{1}{h} \int_{0}^{L} k P(t) V\left(\frac{e^{B t} P(t) q k}{Y(t)}\right) d x \\ & +\frac{1}{h} \int_{z_{0}(t)}^{0} P(t) V\left(\frac{e^{B t} P(t) q k}{Y\left(t_{0}(x)\right)}\right) d x+\frac{1}{h} \int_{t-h}^{z_{0}(t)} k P(t) V\left(\frac{\left.e^{B t} P(t) k q\right)}{\gamma(t)}\right) d x\end{aligned}$

where the first term on the RHS of (4.2) gives the spending of those who have had a paydate in $[L, t] i . e$. , those whose last paydate previous to 0 was in $[L-h, t-h]$; the second term gives the spending (out of bonds) of those people who have had a paydate in $(0, t)$ and have exhausted their cash by time $t$; the third term gives the spending of those who have not yet exhausted their initial cash; the fourth term is the spending of those who have exhausted their initial cash but have not yet had a paydate. Further, $(2.11)-(2.14)$ can be used to find $t_{0}(x)$ as the solution to:

(4.3) $M_{0}(x)=\int_{0}^{t_{0}} P(y) V\left(\frac{e^{B y} P(y) q k}{Y\left(t_{0}\right)}\right) d y$

A very useful aspect of logarithmic utility is that the solution to (4.3), $t_{0}(x)$ does not depend on the price path $P(\cdot)$, only on $q$ and $Y(\cdot)$. This is because $V(x)=1 / x$. Similarly, $P(t)$ drops out of the RHS of (4.2), for a given $t_{0}(x)$ function. Therefore the right hand side of (4.2) is independent of $P(\cdot)$ such that the goods market clears, for a given $r$.

The money market clearing condition, (3.3) may be writen for $t<\bar{t}_{0}$, 
(4.4) $M^{s}(t)=\frac{1}{h} \int_{L}^{t}\left[\int_{t}^{t_{1}(x)} P(y) V\left(\frac{e^{B y} P(y) q}{\gamma(x)}\right) d y\right] d x$

$$
+\frac{1}{h} \int_{z_{0}(t)}^{0}\left[\int_{t}^{t_{0}(x)} P(y) V\left(\frac{e^{B y} P(y) q k}{Y\left(t_{0}(x)\right)}\right) d y\right] d x
$$

where the first term on the RHS is the money holdings of those people who have had a paydate between $o$ and $t$, and the term in brackets is the money holdings at $t$ of someone who had a paydate at $x, M(t, x)$, i.e., someone whose paydate previous to $t=0$ was at $x-h$. Again in the case of logarithmic utility $P(\cdot)$ cancels out of the right hand side of $(4.4)$, since $t_{1}(x)$ given by (2.6) and (2.7) depends only on $Y(\cdot)$. Therefore $q$ on the RHS of (4.4) determines a unique $M^{3}(t)$ consistent with money market clearing and $Y(t)=$ r. QED

The fact that the money supply rule which implements a new price level without changing interest rates must involve a gradual change in $M^{s}(t)$ is seen immediately from (4.4). When $t$ is close to zero, only the second term on the RHS of (4.4) is large. But the second term, evaluated at $t=0$ is just the aggregate money holdings of those who have money at time 0 ; a number which is unchanged by the new monetary policy.

In the case of logarithmic utility a more precise statement can be made :

Theorem 4.2 Assume $u(c)=10 g c$. If a monetary policy is chosen which keeps the nominal rate constant, and which raises the long run price level by $\alpha \%$ then the money supply will increase by less than $\alpha$ for $t>t_{0}$, and then be $\alpha$ higher for $t \geq t_{0}$. i.e. if $M^{-s}(t)$ was the preshock anticipated 
path of the money supply, then an $\alpha$ price level policy will make $M^{S}(t)<$ $(1+\alpha) M^{-S}(t)$ for $t<E_{0}$ and $M^{S}(t)=(1+\alpha) M^{-S}(t)$ for $t \geq E_{0}$.

Proof In the case of logarithmic utility (4.4) may be written for $t<t_{0}$ as

$$
\begin{aligned}
& (4.5) M^{S}(t)=\frac{1}{h} \int_{0}^{t} \frac{\gamma(x)}{q} \frac{e^{-\beta t}-e^{-\beta t_{1}(x)}}{8} d x \\
& \quad+\frac{1}{h} \int_{z_{0}(t)}^{\frac{\gamma\left(t_{0}(x)\right)}{k q}} \frac{e^{-\beta t}-e^{-\beta t_{0}(x)}}{\beta} d x . \frac{1}{}
\end{aligned}
$$

If the monetary policy is designed to raise the price level by $\alpha \%$ and we denote the preshock $q$ by $q_{0}$, then

$$
(4.6) 1 / q=(1+\alpha) / q_{0}
$$

Recalling that $t_{1}(x)$ is unchanged when $q$ changes, the first term on the RHS of (4.5) increases by $\alpha$ when $q$ changes. If we let $B(t)$ represent the preshock value of the first term on the RHS of (4.5) we can write (4.5) as (4.7) $M^{S}(t)=(1+\alpha)(B(t)+g(\alpha, t))$, where (4.8) $g(\alpha, t)=\frac{1}{h} \int_{z_{0}(t)}^{0} \frac{\gamma\left(t_{0}(x)\right)}{k q_{0}} \frac{e^{-\beta t}-e^{-\beta t_{0}(x)}}{\beta} d x$. Note that (2.18) can be used to show that for each $x, t_{0}(x)$ is an increasing function of $q$ and hence a decreasing function of $\alpha$, by (4.6). Therefore 
when $\alpha$ rises the integrand on the RHS of (4.8) falls. Further, since $z_{0}(t)$ is the inverse function of $t_{0}(x), z_{0}(t)$ will rise when a rises. Hence $g(\alpha, t)$ is a decreasing function of $\alpha$. Recall that $B(t)+g(0, t)$ gives the preshock anticipated money supply at $t$. Hence from (4.7) the post snock money supply will rise by less than $\alpha$ for $t \varepsilon\left[0, \bar{t}_{0}\right.$ ) when a new monetary policy is chosen at time 0 as given by (4.6). We have already shown that for $t \geq t_{0} M^{S}(t)$ rises by $\alpha \%$. QED

Theorem 4.2 is illustrated by Figure 4.1 . Figure 4.1 is derived from a discretization of the continuous time mode, where 1 period is equal to a day. It is assumed that $B=3 \%$ per year, and $k$ is chosen so that there is a steady state holding period of 30 days, i.e. $\exp ((30 / 365) B)=k$. The pay period $h$, is chosen to be 50 days. In the steady state the economy holds approximately $30 / 2$ days worth of spending in the form of money. The only role of $h$ in these simulations is that a consumer's exhaustion interval must be less than $h$. If $h$ is made smaller than $\underset{z}{\operatorname{Max}} t_{0}(z)$ then it will affect the Figure by making the movement to the new steady state occur sooner. The first graph (on the top) of Figure 4.1 shows the paths of money, for which it is a general equilibrium for the interest rate to be unchanged (1.e., $r=$ $B=3 \%$ per year) corresponding to various price level policies. 2 It can be seen that when $\alpha$ rises, money gradually rises to its new level of $1+\alpha$. When $\alpha$ falls it takes somewhat longer for money to reach the new steady state because $t_{0}(z)$ rises and the persistence of the non steady state behavior is determined by how long it takes those people with money at time zero to exhaust that money. Another nonlinearity between positive and negative shocks is that the money stock actually jumps down at time 0 when $\alpha$ 
$=-.5$, as people find it optimal to bear the transactions cost of making a deposit at a date which is not a pay date.

The effect of an $\alpha$ price level policy on the price level in the short run is similar to the effect on the money supply. This is because those people who have money at the time of the shock will not want to increase their spending by $\alpha$ since this will require too rapid exhaustion of cash and thus incur an excess of transactions costs. It can be shown that prices at first $r$ ise by less than $\alpha \%$.

Theorem 4.3 Assume that $u(c)=10 \mathrm{~g} c$. If the money supply path at time 0 is chosen to keep interest rates unchanged and to lead to an $\alpha \% \mathrm{rise}$ in the price level (i.e., $(4.6)$ is satisfied), then $P\left(0^{+}\right)$will $r$ ise by less than $\alpha \%$.

Proof In the case of logarithmic utility, (4.2) becomes, for $t=0$

$$
P(0) Y(0)=\frac{1}{h} \int_{z_{0}(0)}^{0} \frac{\gamma\left(t_{0}(x)\right)}{k q} d x+\frac{1}{h} \int_{-h}^{z_{0}(0)} \frac{1}{q} d x .
$$

Using (4.6) this may be written as

(4.9) $h Y(0) P(c)=(1+\alpha)\left[\int_{z_{0}(0)}^{0} \frac{Y\left(t_{0}(x)\right)}{k q_{0}} d x+\int_{-h}^{z_{0}(0)} \frac{1}{q_{0}} d x\right]$

Recall that from (2.18) a rise in $\alpha$, (equivalent to $q<q_{0}$ ) implies that $t_{0}(x)$ falls for each $x$. Note that $z_{0}(0)$ is unchanged by the policy 
announcement. Therefore, as $\alpha$ rises the term in brackets in (4.9) will fall. The proof is completed by noting that the term in brackets gives the value of $h Y(0) P(0)$ when there is no shock, i.e, when $\alpha=0$. (The assumption that $Y(t)$ and $n$ are exogenous should be recalled.) QED

The second graph on Figure 4.1 shows the path of prices for various values of $\alpha$. Recall that consumers own the "stores" which sell the output Y. The present value of the nominal output of stores rises after the future price level rises. Hence consumers feel nominally wealthier. It can be seen that the price level response is almost immediate. This is because it is feasible for all consumers, even those who have not made a withdrawal, to plan to increase their nominal spending when they feel nominally wealthier. For those people who have not made a withdrawal, this is accomplished by planning to exhaust their money holdings sooner than they would have had their wealth not increased. $\underline{3}^{\prime}$

The third graph on Figure 4.1 shows the path of real balances for various a shocks. Recall that in the standard LM model the only monetary policy consistent with constant nominal interest rates are those for which real balances are unchanged by the price level policy announcement. In our model a rise in the price level $(\alpha>0)$ causes an initial fall in real balances and then a gradual $r$ ise in real balances to return it to the old steady state level. This is a reflection of the fact that spending (and thus prices) respond faster to the increase in nominal wealth than does the aggregate stock of money.

Figure 4.2 plots the path of money prices and real balances for $\alpha=1 \%$ for various values of $\underline{k}=k-1$. As $k$ varies the pre-shock money supply is always normalized to $\$ 1$, so each curve shows the time it takes for money to 
rise by $a:$ for a given $k$. A very large value of $\underline{k}$, say $5 \%$ induces people to spend only out of cash, and the money holding period is the period between paydates. This generates an equilibrium path identical to the model in Grossman-Weiss [1983] where the money holding period was exogenously fixed. As we noted earlier, an unanticipated a price level policy generates a path of money winich gradually rises to a level $\alpha$, higher than the previous steady state. If $\underline{k}$ is so large (5\% in Figure 4.2) that people prefer cash to bonds as a transactions medium, then a small drop in $\underline{k}$ will not change the path of money (for a given $\alpha$ ). As $\underline{k}$ falls sufficiently below 5\%, it will take longer for money to $r$ ise say half way to the new steady state because the exhaustion time of those people who have not had a paydate in the interval $(0, t)$ falls, but in the above range of $k$, the exhaustion time of those people who have had a paydate $z$ in $(0, t)$ will still be $z+h$ (this occurs in the Figure as $\underline{k}$ falls from $5 \%$ to $.5 \%$ ). Thus the first group will be holding relatively less money and the second group will be holding the same amount of money than would occur at a higher $\underline{k}$. As $\underline{k}$ falls further it will eventually be the case that those people with a paydate in $(0, t)$ find it optimal to set an exhaustion time before their next paydate. This means that at the old steady state, each person was planning to exhaust before his next paydate. Hence the unanticipated $(\alpha>0)$ price policy surely causes all people to exhaust before their next paydate. This means that a fall in $\underline{k}$ lowers the fraction of the total money supply which is held by those people who have not had a withdrawal before time $t$. Since the group who have had a withdrawal before $t$ are holding their new steady state level of money, the aggregate money supply is closer to its new steady state value by $t$, than occurs at a slightly higher $\underline{k}$ (this occurs as $\underline{k}$ falls from .24 to $.05 \%$ in the Figure). 
The second graph in Figure 4.2 gives the price path for various values of $\underline{k}$. It can be seen that as $\underline{k}$ gets smaller the spending of consumers gets closer to the steady state level sooner. The non-monotonicity apparent in the first graph does not appear, because the fall in exhaustion times of those people who have not had a paydate before $t$ increases their spending and this reinforces all the other effects mentioned above.

The third graph in Figure (4.2) grapns real balances for various values of $\underline{k}$. The first interesting aspect of the Figure is that $\underline{k}=5 \%$ is quite different from all the other paths. When $\underline{k}=5 \%$, the shock at time zero does not cause any consumer to change his holding period. Real balances rise at first because the consumers who have a paydate at t hold more than their pro-rata share of cash, since consumers who have not yet exhausted their time 0 cash stocks hold less than their pro-rate share of cash. As $t$ rises the fraction of consumers with a paydate since time zero rises sufficiently high that most of the money in the economy is held by people who have made a withdrawal and thus incremented their cash balances. For smaller values of $\underline{k}$ a non-monotonicity appears for the same reason as in the Money Figure. 
Money

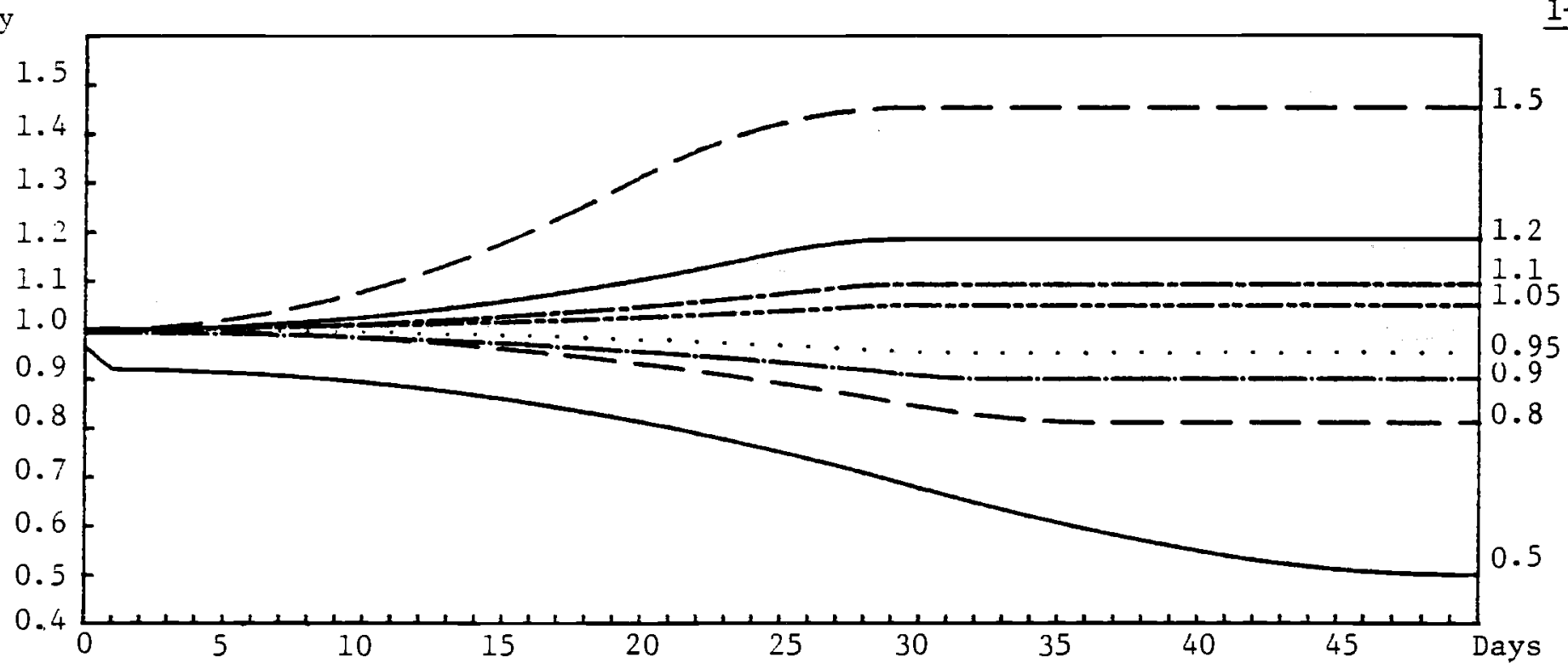

Price

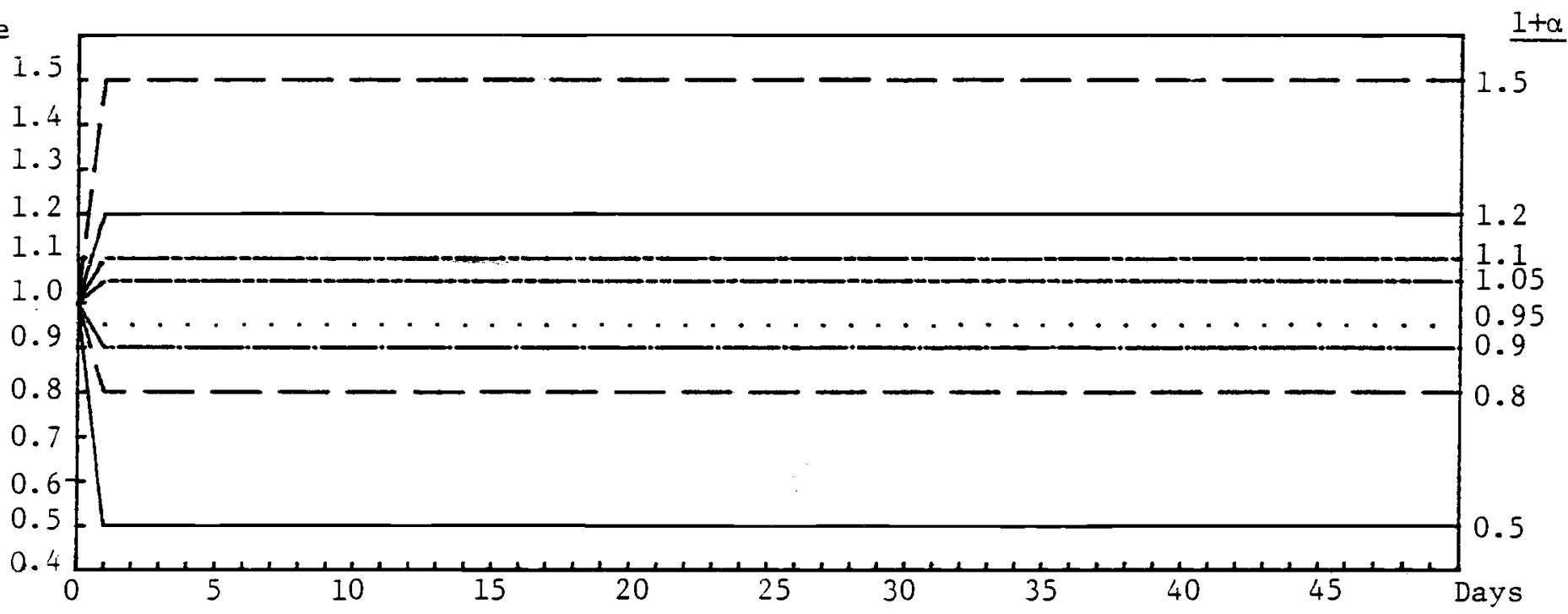

Real

Balances

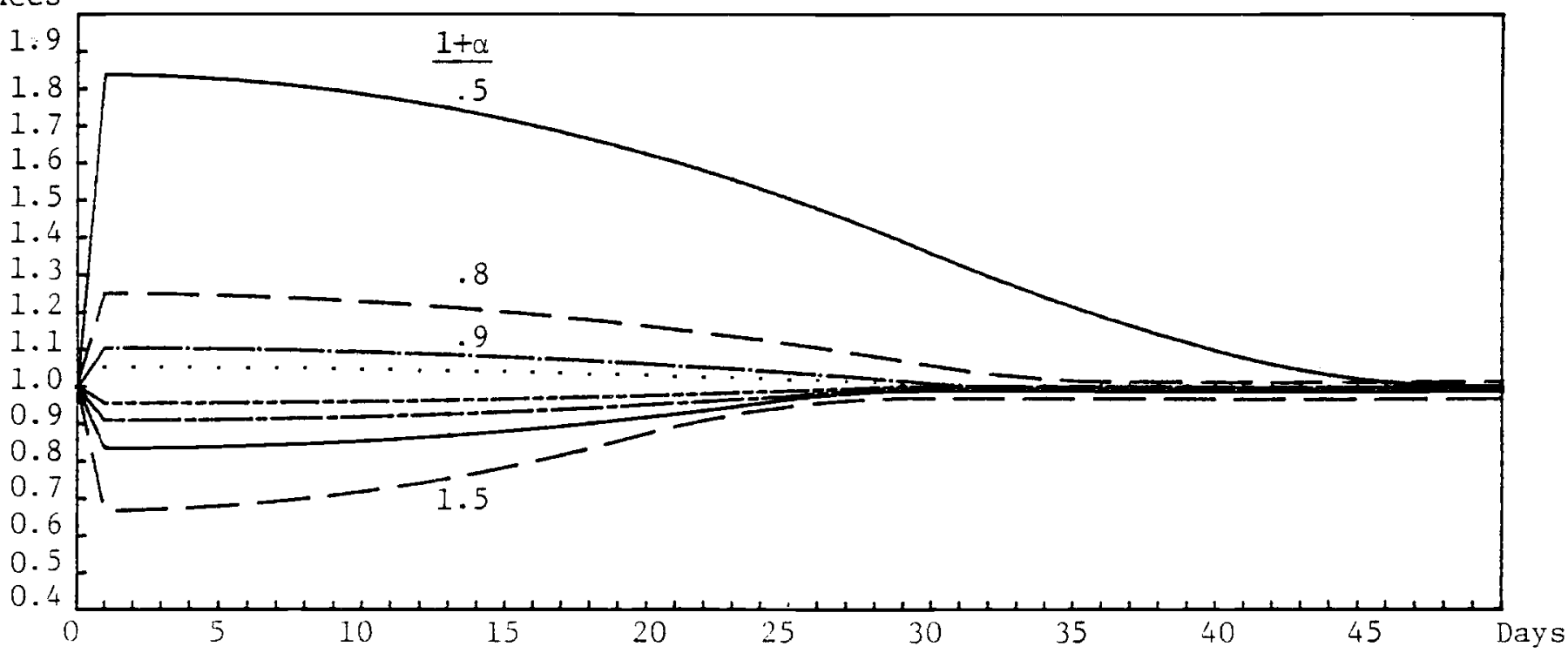


Eigure 4.2: Effect of Changing Transactions Cost on $1 \%$ Price Level Policy
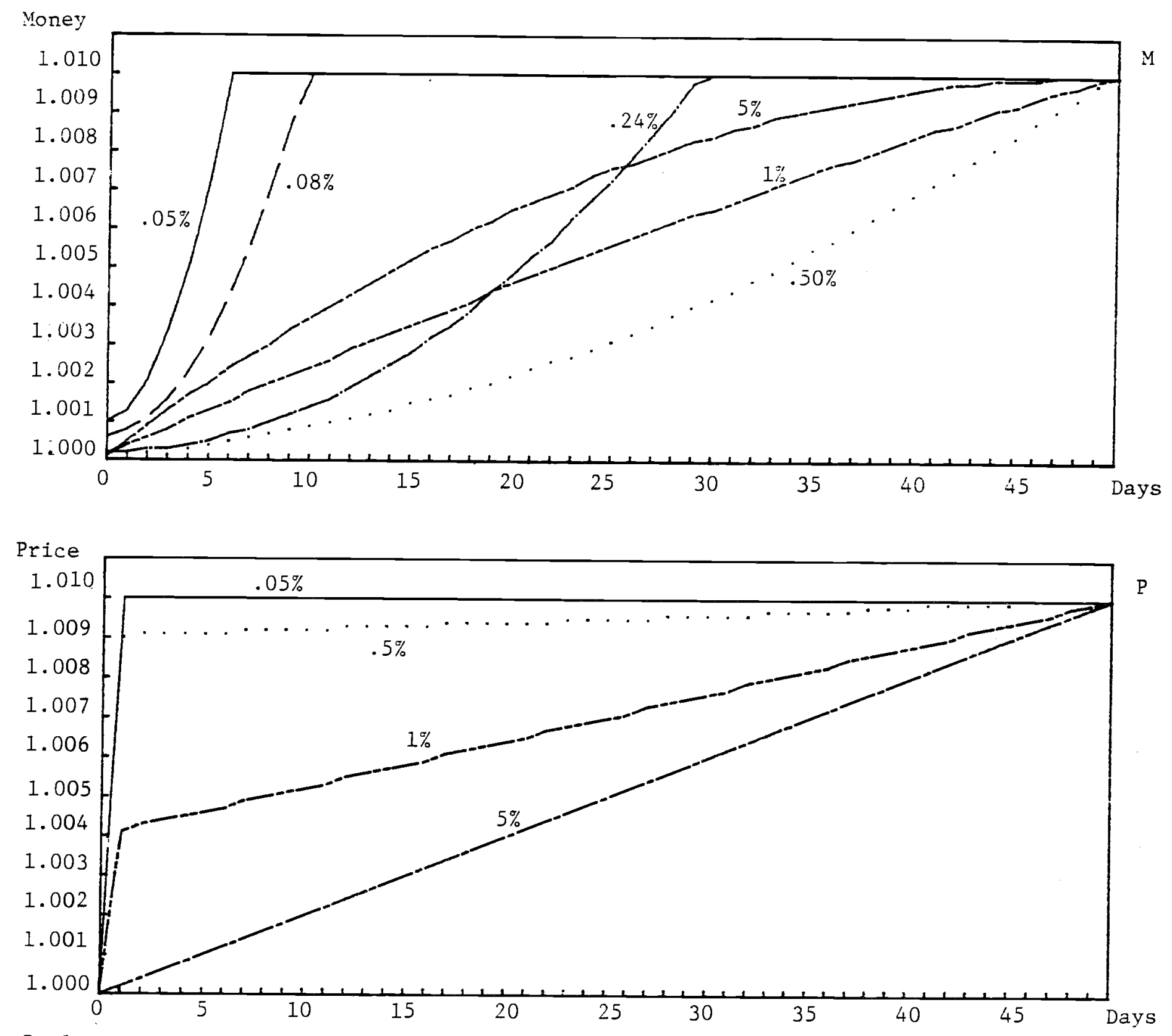

Real

Balances

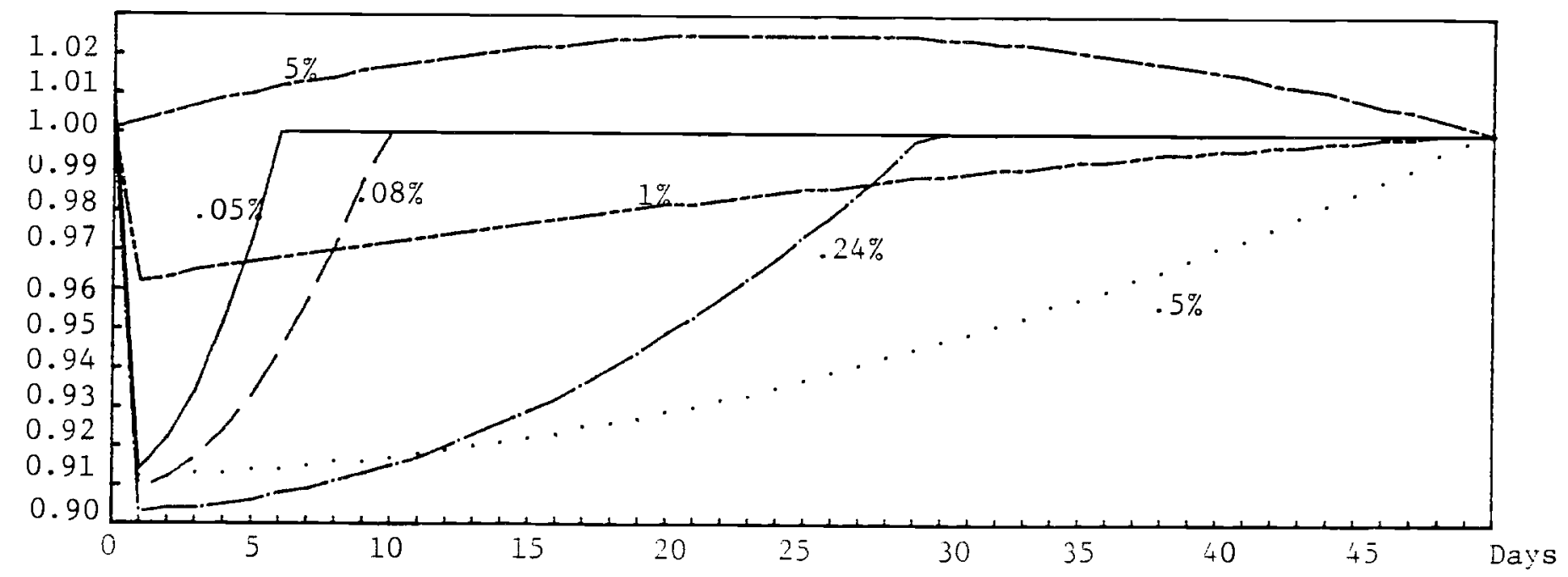




\section{Interest Rate Policies}

In the standard LM model, if an interest rate $r(t) \equiv r>\beta$ is chosen, then in a general equilibrium the money supply must be growing for $t>0$. In that model consumers (correctly) expect inflation so they immediately increment their cash holdings. In contrast with the standard LM model, the model considered here can, for example, have $r-\beta>0$ and yet the money supply will be falling. This is because consumers do not find it optimal in the face of a rise in the inflation rate to immediately increment their cash balances. Instead there is a liquidity effect, where a contractionary monetary policy is needed in the short run to implement a higher interest rate. That is, a rise in interest rates will be associated with those consumers who have a stock of money at the time of the announcement holding less money than before (rather than more) because of a desire to exhaust their money sooner when interest rates $r$ ise.

As is well known any discussion of interest rate policies must specify an additional nominal magnitude before a well defined money supply rule exists, see e.g., Sargent and Wallace (1975). In the standard LM model, it is necessary to specify an additional nominal magnitude e.g.. $M_{0}$. In the model developed here it is also necessary to specify a nominal magnitude, and we implement this through $q$. The simplest interest rate policy to analyze is one where the change in the interest rate is permanent. Recall that changes in $q$ represent long run changes in the level of the money supply. Note that after at most $h$ units of time, every consumer has exhausted his initial money stock. Further, any money held by a consumer at $t>h$, is derived from a withdrawal made after the new interest rate has 
been announced. Thus for $t>h$, and $r(t) \equiv r$, the money market clearing condition is

(5.1) $M(t)=\frac{1}{h} \int_{t-\tilde{t}}^{t} M(t, z) d z$,

where $\bar{t}$ satisfies (using $(2.6)$ and (2.7)):

(5.2) $r \dot{t}=108 k$

under the assumption, which we shall maintain, that $\bar{t}<h$. Under the assumption of logarithmic utility, and $r(t) \equiv r \equiv B+\pi(2.7)$ and (2.15) can be used to write $(5.1)$ as

(5.3) $M(t)=e^{\pi t} \int_{0}^{\tilde{t}} e^{-r \tilde{t}}\left[\frac{e^{r y}-e^{\pi y}}{\beta q h}\right] d y$ for $t>h$,

Thus, changes in $q$ change the long run level of the money supply in a proportional manner.

The short run dynamics of the money supply is more complicated. This is because, by (2.18), the initial exhaust time of consumers who have money at the time of the shock depends on $q$ as well as $r$. Equation (4.5) can be used to compute the rate of change in money at time 0 :

(5.4) $\dot{M}(0)=\left[\frac{1-e^{-\beta t_{1}(0)}}{q \beta h}-\int_{z_{0}(0)}^{0} \frac{\gamma\left(t_{0}(z)\right)}{q k h} d z\right]$ 
where the first term on the RHS is the money withdrawn by the person with a paydate at time $0.1^{\prime}$ The second term is the spending out of money. Thus (5.4) states that the flow of money into the economy must equal the difference between the flow increases in money holdings generated by consumers with paydates, and the flow decrement in money holding by consumers spending out of money.

We will be able to show that if $q$ is unchanged by the monetary policy and any interest rate policy is chosen for which $r(t)>\beta$ for $t \varepsilon[0, h]$, then $M(0)<0$, i.e., a higher interest rate is associated with a contracting money supply. Recall that a fall in $q$ is associated with a higher price level policy. If the interest rate policy is combined with a sufficiently strong price level policy, then arbitrarily large inflation can be generated between $t=0$ and $t=h$. In such an extreme case the liquidity effect associated with a higher interest rate is overwhelmed. If $q$ only falls by enough to keep money withdrawn at $t=0$ unchanged when $r$ rise above $B$, then we will show that the expansionary price level policy does not overwhelm the liquidity effect associated with a rise in $r(t)$. We now show that if $q$ is permitted to change in the following two ways then a $r$ ise in $r(t)$ will be associated with a fall in the money supply: (i) if q falls no more than necessary to keep money withdrawn at $t=0$ unchanged by the shock; or (ii) if $q$ rises when $r$ rises.

Theorem 5.1

Assume $u(c)=\log c$, and the preshock steady state involves no inflation. Let a new interest rate policy $r(t)$ and price level policy $q$ be chosen such that $r(t)>B$ for $t \varepsilon[0, h]$. (i) If $q<q_{0}$ and $q$ satisfies 
(5.5) $\frac{1-e^{-\beta t_{1}(0)}}{q} \leqq \frac{1-e^{-\beta E}}{q_{0}}$,

where $q_{0}$ and $\bar{t}$ are respectively the pre-shock values of $q$, and the exhaust time corresponding to $r=\beta$, then the money supply will initially contract. (ii) If $q \geq q_{0}$, then the money supply will initially contract.

\section{Proof}

Recall that in preshock steady state the money supply is constant. Thus we need only show that $M(0)<0$.

Case (i) $q \leq q_{0}$ : Under condition (5.5) the first term on the RHS of (5.4) clearly is lower than its pre-shock value. It remains to show that the second term on the RHS of (5.4) rises. Rewrite (2.18) as

(5.6) $k B M_{0}(z)=\left(1-e^{-\beta t_{0}(z)}\right) \frac{\gamma\left(t_{0}(z)\right)}{q}$.

When $q$ falls, $\gamma(t) / q$ rises for each $t$. Hence $t_{0}(z)$ falls for each $z$ when $q$ falls. But $1-e^{-\beta t_{0}}$ is a monotone increasing function of $t_{0}$, so $\frac{\gamma\left(t_{0}(z)\right)}{q}$ rises when $Y(\cdot) / q$ rises. Therefore the second term on the RHS of $(5.4)$ rises.

Case (ii) $q \geq q_{0}$ Let $t_{0}(z ; q)$ denote the solution to $(5.6)$ for $t_{0}$ where $q$ appears explicitly as a determinant of $t_{0}$. First $f i x q$ and raise $r(t)$ for each $t$; clearly from 
(5.6) this cause $t_{0}(z ; q)$ to fall. But $1-e^{-B t} \circ$ is a monotone increasing function so, $\gamma\left(t_{0}(z ; q)\right)$ must rise when $\gamma(\cdot)$ rises. Next rewrite $(5.4)$ as

$$
\dot{y}(0)=\frac{1}{q h}\left[\frac{1-e^{-8 t_{1}(0)}}{3}-\int_{z_{0}(0)}^{0} \frac{\gamma\left(t_{0}(z ; q)\right)}{k} d z\right]
$$

From $(2.7), t_{1}(0)$ clearly falls when $Y$ rises, thus $\dot{M}(0)$ becomes negative as $Y(\cdot)$ rises for a given $q$. Next $f i x ~ Y(\cdot)$ and raise $q$. From $(5.6)$, to $(z ; q)$ is an increasing function of $q$. Hence $\dot{M}(0)$ becomes negative when $q$ rises for a given $\gamma(\cdot)$.

(It should be recalied that $z_{0}(0)$ is the paydate of someone who has just exhausted his money at time zero; and this is clearly unaffected by a change in $q$ or $r(\cdot)$ at time zero.) QED

Before presenting numerical simulations of money supply paths which implement monetary policies, it is of interest to mention one other method of choosing $q$. In the standard LM model it is possible to implement a new interest rate policy at time 0 and keep the money supply at time zero unchanged from its pre-announcement value. (of course, such a monetary policy would lead to a jump in the price level at time 0. ) Further, in the LM model every interest rate $r(t)$ is given by $r(t)=\beta+P / P$, and if $M / P=$ $L(r)$, then any $\dot{P} / P$ may be implemented by the $M$ which satisfies $(5.7) \frac{M}{P}=L(B+\dot{P} / P)$. 
Eq. (5.7) can be solved for $M$ at an arbitrary time $T$, as

$$
M(T)=M(0) Y(T) e^{-B T} L(r(T)) / L\left(r\left(0^{+}\right)\right)
$$

Hence if an interest rate policy is announced where $r(T)=r\left(0^{+}\right)$then the level of money at time $T$ should increase by a factor of $Y(T) e^{-\beta T}$, relative to $M(0)$.

Thus, when the change in $r(\cdot)$ is permanent so that $r(T)=r\left(0^{+}\right) \equiv$ $r(t)=r$ we can calibrate the price level effect of the shock to be the same in our model as in the LM model where $M(0)$ is unchanged. In the case where the change in $r$ is permanent, (5.3) may be used to choose $q$ such that at $T=$ $h$ (by which the short run effect of the shock is over) $M(T)=e^{\pi T} M(0-)$.

Figure 5.1 a shows the effect of a permanent increase in the interest rate by $10 \%$, i.e., from $r=B=.03$ to $r=.033$. Curves are drawn for 3 values of $q$. The first is for $a_{L M}$ which corresponds to the long run money supply increase generated in the LM model when $M(0)$ is not allowed to jump; the second denoted by $q_{u}$ corresponds to a decrease in $q$ which just keeps the money withdrawn of those at the bank at the time of the announcment uncinanged; the third sets $q=q_{0}$. Figures $5.1 \mathrm{~b}$ and $5.1 \mathrm{c}$ show corresponding curves for the price level and real balances respectively. $\underline{\prime}$ Figure 5.1 a shows the liquidity effect for $q=q_{L M}$ most clearly. There is a fall in money for 10 days to accomodate the desire of those people who have not "been to the bank" to reduce their money holdings. As the fraction of money held by those people who have not been to the bank falls, the curve rises to its new steady state rate of growth (which looks flat only because of the scale of the Figure). The curve labelled $q_{u}$ shows the effect of choosing a $q$ larger than $q_{L M}$. It has the same liquidity effect, but is 
associated witn a lower steady state path of money. The final curve in Figure 5.1a, labelled $q_{0}$, shows the effect of keeping $q$ equal to its pre snock value. The decrease in the money holding period causes a fall in money demand which is not compensated for by an increase in perceived nominal wealth.

Figure 5.10 shows the price paths associated for the various values of q. It simply reflects the fact that $q_{0}>q_{u}>q_{L M}$. The value of the price level at time $t$ is plotted relative to the premshock steady state level. Note that $q=q_{0}$ leads to essentially no cnange in the price level when the new interest rate policy is announced. Figure $5.1 \mathrm{c}$ combines the previous two figures to generate a path of real balances. In the standard LM model real balances immediately fall to their new steady state level, while here there is a delayed response.

\section{DISCUSSION OF FIGURES 5.2 TO 5.4}

Figure 5.2 shows the effect of a temporary increase in the interest rate from 3\% to $4 \%$ which lasts for 100 days. The lower section of the Figure snows the path of interest rates, while the upper section shows the path of money (denoted by $M$ ) and inflation (denoted by $\pi$ ). For this Figure and all the Figures which follow, $q$ is set equal to $q_{0}$. The inflation rate is given by the broken line, and the units (in percent per year) are given on the right hand vertical axis in the Figure. There is an initial jump in the price level indicated by a very high inflation rate at time 0 . Then for about 20 days, an inflation rate of about $.5 \%$ associated with the fact that the people who have not yet had a paydate do not increase their spending rate by $1 \%$, since this would cause them to bear an excessive transactions cost. The period between 20 and 30 days in a transitional one 
in which all those people who had money stocks at date zero are just about exhausted. Indeed at around $t=30$, the inflation rate jumps as the spending out of money in the economy becomes solely generated from those consumers who have had a paydate after $t=0$. Between $t=30$ and $t=70$ all money is held by people who know that interest rates will be 4 until their next paydate, so the economy has reached a temporary steady state associated with $r=4 \%$. The inflation rate is $1 \%$. Note that at around $t=$ 80, the money supply starts growing to accommodate the fact that the people making a money withdrawal anticipate a fall in interest rates during their pay-period. In comparing Figure $5.1 \mathrm{~b}$ with Figure 5.2 , it should be noted that for each $q$, prices are indeed varying over time in Figure 5.1b, however the scale of the graph is such that these variations cannot be seen. Figure 5.3 is similar to Figure 5.2 except that the interest rate policy lasts only 10 days. This sharp rise and fall of interest rates occurs within the length of a single pay-date, and more importantly, within the length of a single money holding period. As a consequence, the inflation rate never attains the $1 \%$ level even though the nominal interest rate is above the rate of time preference by $1 \%$. Figure 5.4 is also similar, but the interest rate policy lasts for 50 days, which is long enough so that at around $t=30$ everyone in the economy faces the $4 \%$ interest rate for almost a whole money holding period, so that the inflation rate does rise to 1\% for a short period. The figures show that the real rate of interest on bonds $r$ ises in short run when there is a monetary policy designed to raise the nominal rate of interest. It also is clear that the nominal interest rate is not highly correlated with the expected rate of inflation when these rates are measured over periods of length equal to the average holding period of money in the economy. 


\section{DISCUSSION OF FIGURES 5.5 TO 5.8}

The next set of numerical simulations concern permanent monetary policies. Here we are interested in the economies response to oscillatory interest rate policies. In these Figures $\omega$ denotes the frequency of oscillation in interest rates, relative to the pre-shock steady state, that is, in the pre-shock steady state the money holding period is 30 days, and thus $\omega=2$ denotes an interest rate sine curve that has a period of 15 days. 3 ' As we move from Figure 5.5 to Figure 5.8 the period for one interest rate cycle rises from a period of 12 days $(\omega=2.5$ ) to a period of 120 days $(\omega=.25)$. Though the money supply path is qualitatively the same in all the Figures, there are important quantitative differences. The first thing to note is that the money scale is different on each of the Figures. As $w$ falls, the size of the money supply movement consistent with the interest rate path rises. When $\omega=2.5$ (Figure 5.5) the money supply oscillations are on the order of $1 \%$. However, by Figure 5.8 the money supply oscillations are on the order of $50 \%$. In all cases interest rates are oscillating by as much as $33 \%$. When the interest rate oscillates very rapidly around the steady state of $r=3 \%$ the optimal money exhaustion time changes very little relative to the case where $r=3 \%$. This is because the accumulated interest over a given period of time determines the money holding period, and if interest rates vary very rapidly around $3 \%$ then the accumulated interest will be very close to the value it would have if interest rates were constant at $3 \%$. These Figures thus iliustrate the fact that rapidly varying interest rates will have very little effect on money demand.

The next interesting aspect of the Figures is that money and interest rates are negatively correlated. A rise in the nominal interest rate lowers 
the desired money holding period, and also lowers money demand. Note that in the Figures $M$ and $M / P$ are plotted together. This is because prices are measured relative to the pre-shock steady state, and are thus sufficiently close to 1 that given the scale of the Figures $M$ is sufficiently close to $M / P$ as to be indistinguishable.

Another interesting aspect of the Figures is that, though interest rates and inflation are roughly in phase, it is false that $\pi(t)=r(t)-B$ even after the economy reaches the new steady state. This is because the spending of consumers is varying with time due to the fact that the money exhaustion period is time varying. This effect is in addition to the effect that consumers desire a rate of growth in nominal spending of $r(t)-\beta$ for a given money holding period. Further, at any point in time different consumers have spending determined by interest rates over different periods, so there is a time averaging of the interest rate which determines nominal spending growth for a given money holding period.

Further note should be made of the initial effect of the new interest rate policy. The interest rate policy is designed such that interest rates initially rise. In all the Figures this leads to a jump in the price level and a fall in the money supply. Thus a rise in interest rates is associated with a contractionary monetary policy.

As in the temporary interest rate policy figures, there is a transitory effect at the time $\bar{t}_{0}$ in the inflation rate associated with the final exhaustion of the stock of cash present at the announcement date of the new policy (i.e., present at $t=0$ ). The shift in monetary policy is also apparent at $\bar{t}_{0}$.

It is interesting to note that if $\omega=1$, then each consumer who makes a withdrawal will choose the same money holding period under the 
oscillatory policy as he would have chosen under $r=3 \%$ in the old steady state. If we had included such a Figure it would have shown the money supply at 1 (the old steady state) for $t>t_{0}$ and a small liquidity effect for earlier values of $t$. Some of this is apparent in Figures 5.6 and 5.7 where the average level of the money supply changes after $\bar{t}_{0}$. In each case the fact that $\omega$ is not equal to 1 changes the long run average holding period. For example in Figure 5.7 the long run average money supply falls below the pre-shock steady state because the average person is choosing a lower exhaustion time at $\omega=.9$ than at $\omega=1$.

\section{DISCUSSION OF FIGURES 5.9 AND 5.10}

Figure 5.9 shows the path of money and inflation when the transactions cost is sufficiently small that people exhaust their money in one day $(k=$ $1+8 * 10^{-4}$ ) and $\omega=.25$. It can be seen that the short run effects described earlier are absent, and more importantly that $\pi(t)=r(t)-\beta$. Figure 5.10 involves a choice of the transactions cost such that people never find it optimal to exhaust their cash in between pay periods ( $k=$ infinity). This corresponds to the Grossman-Weiss (1983) model. The first thing to note is the scale on the money axis. As we pointed out in Section 3 there is virtually zero interest elasticity of the demand for money in this case, so that the movements in money are extremely small relative to Figure 5.8 . Next note that the price level does not jump, so that $M / P$ diverges from $M$. In addition the inflation rate is damped relative to $r(t)-\beta$ because of the fact that the spending rate at $t$ of a consumer who had a paydate at $z$ is $Y(z) e^{-B t} / q$ by $(2.16)$. Hence aggregate spending at $t$ is determined by an average of interest rates over a period from $t$ to $t-\bar{t}$. In particular it can be shown that 


$$
\pi(t)=-\beta+\frac{Y(t)-Y(t-\bar{t})}{\int_{t \rightarrow E}^{t} Y(z) d z},
$$

So the inflation rate at $t$ depends on interest rates from $t-\bar{t}$ to $t$. 


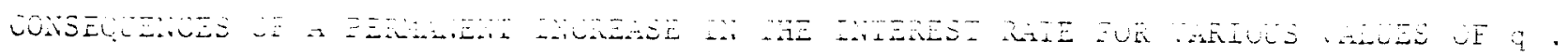

Figure 5.la

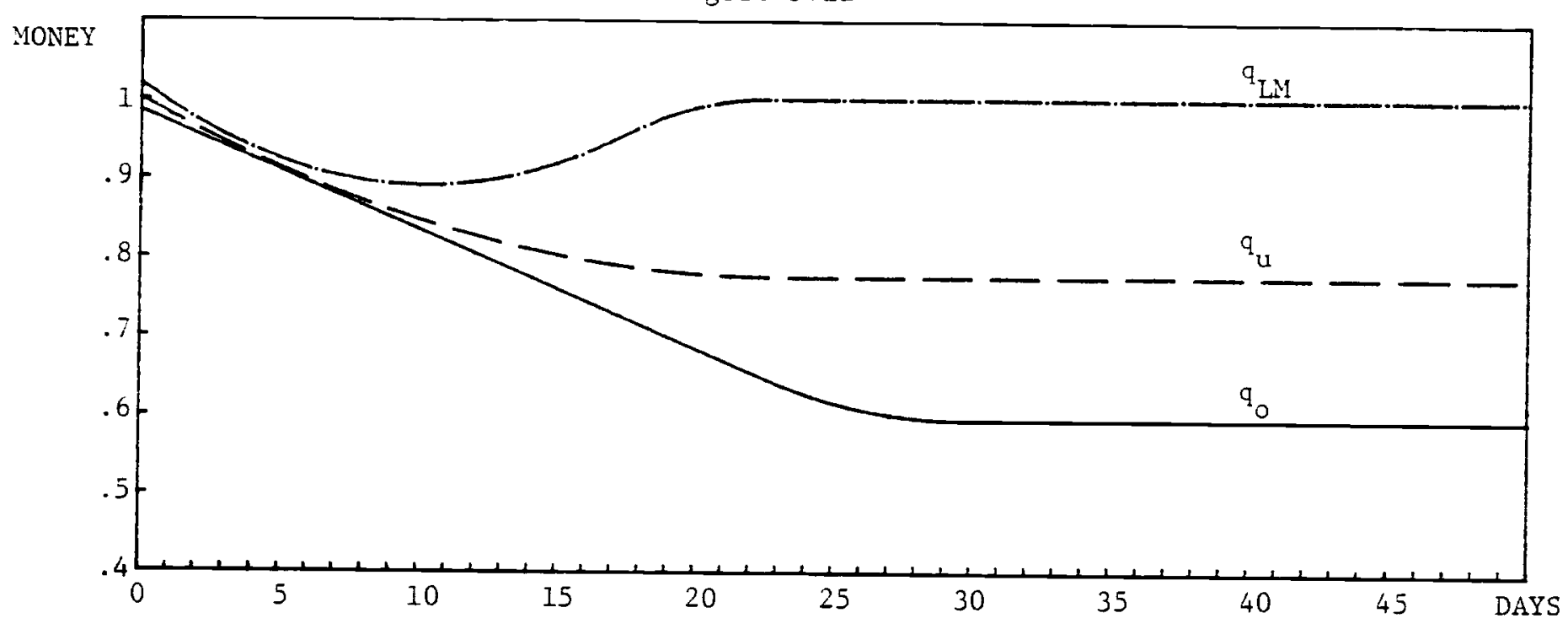

Figure 5.1b
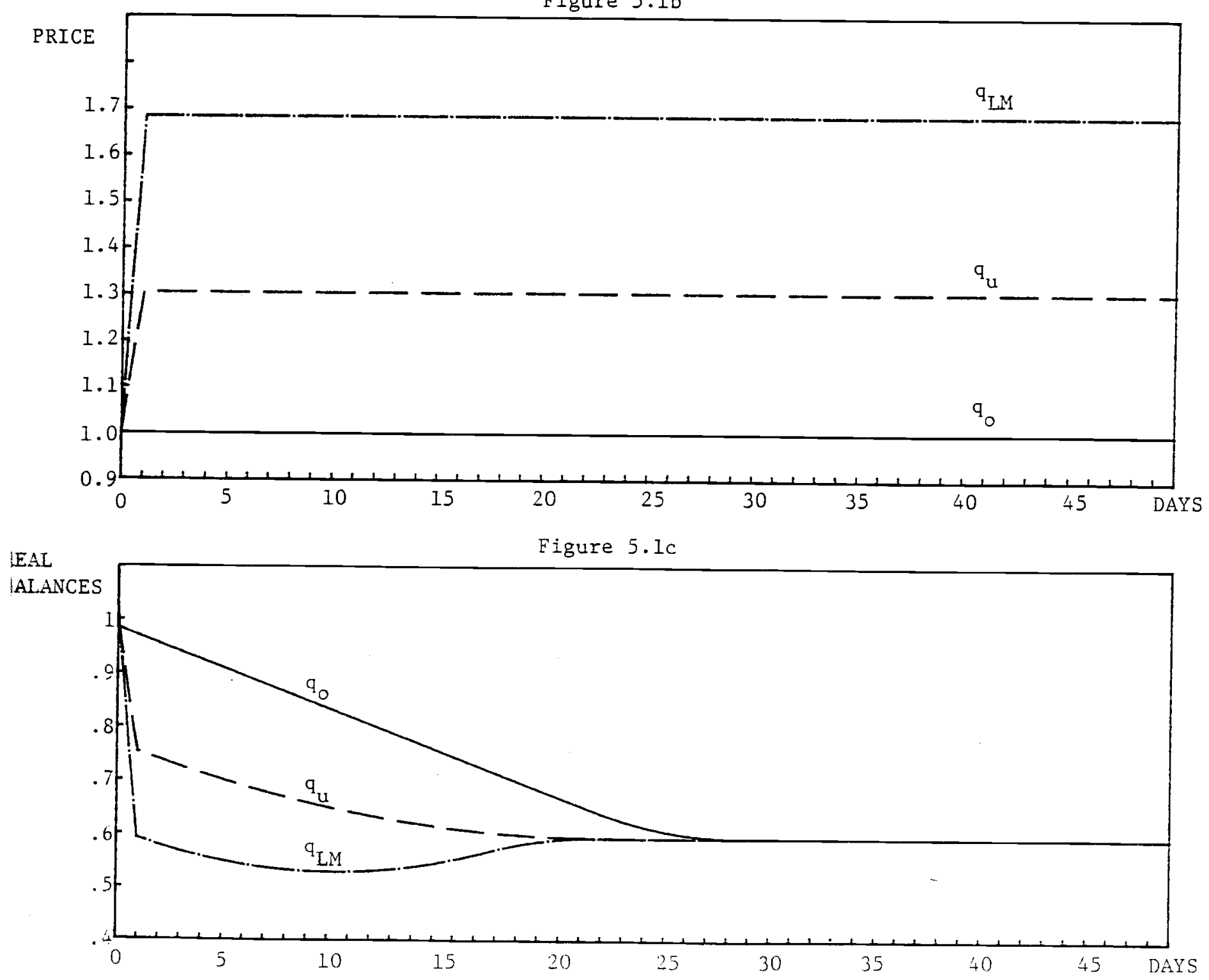
Consequences of a Temporary, but Long Iived Rise in the Interest Rate

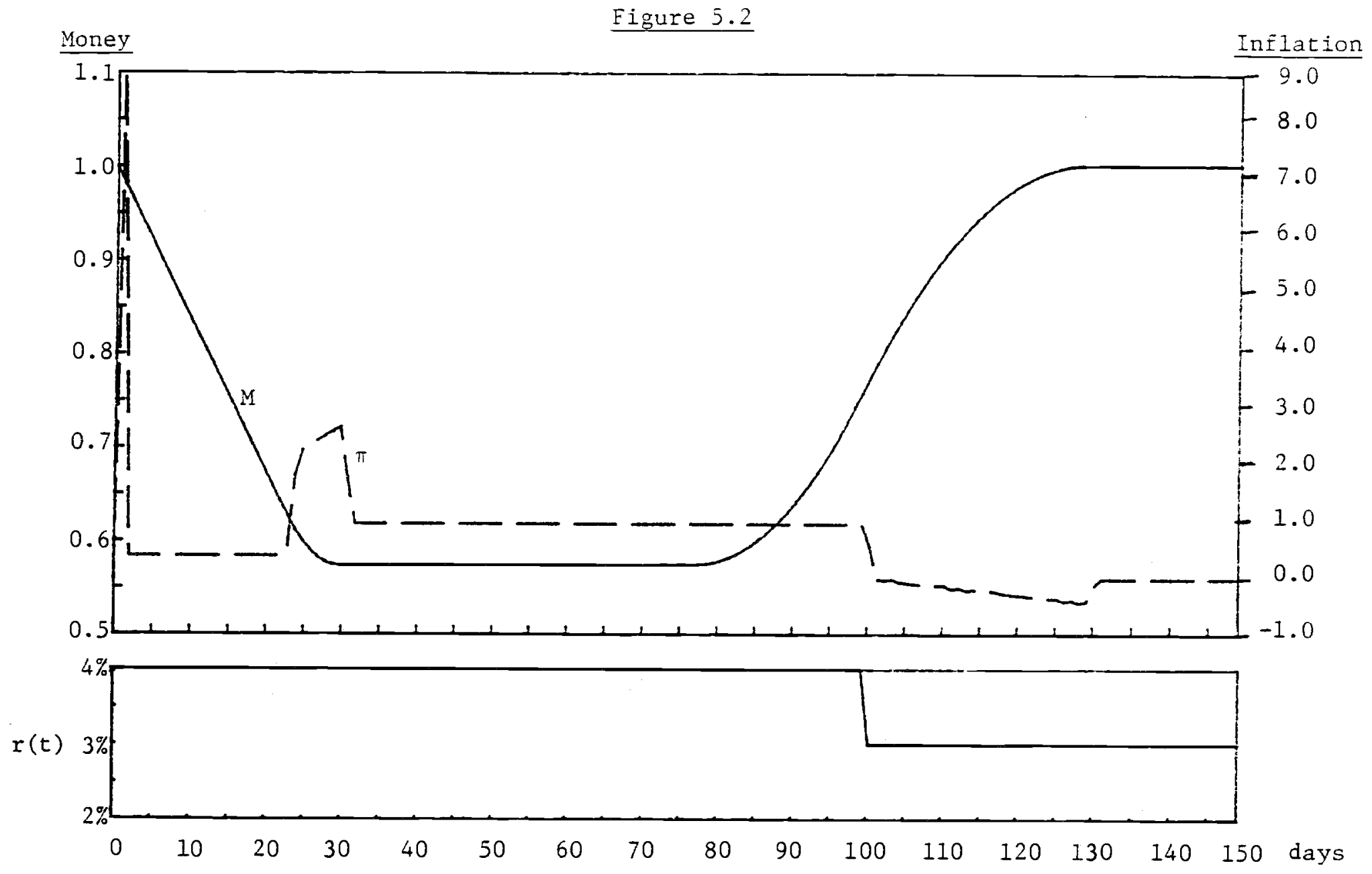




\section{Figure 5.3}

Yoney

Inflation

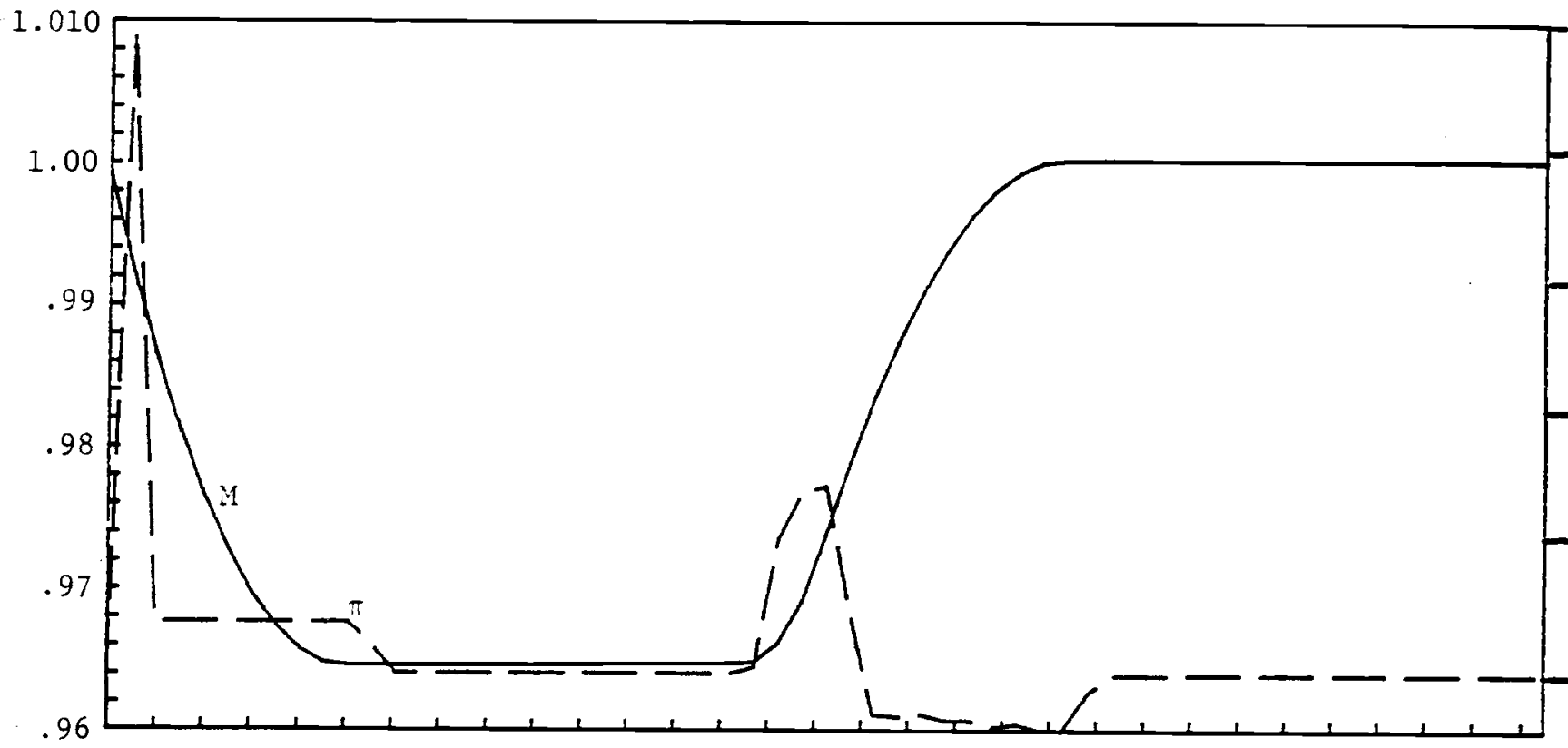

5.00

4.00

3.00

2.00

1.00

0.00

$r(t)$
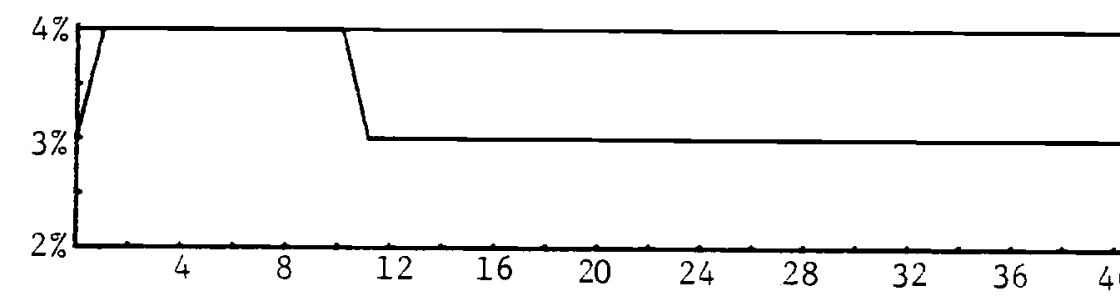

Figure 5.4

Money Consequences of an Intermediate Term Rise in the Interest Rate

1.01

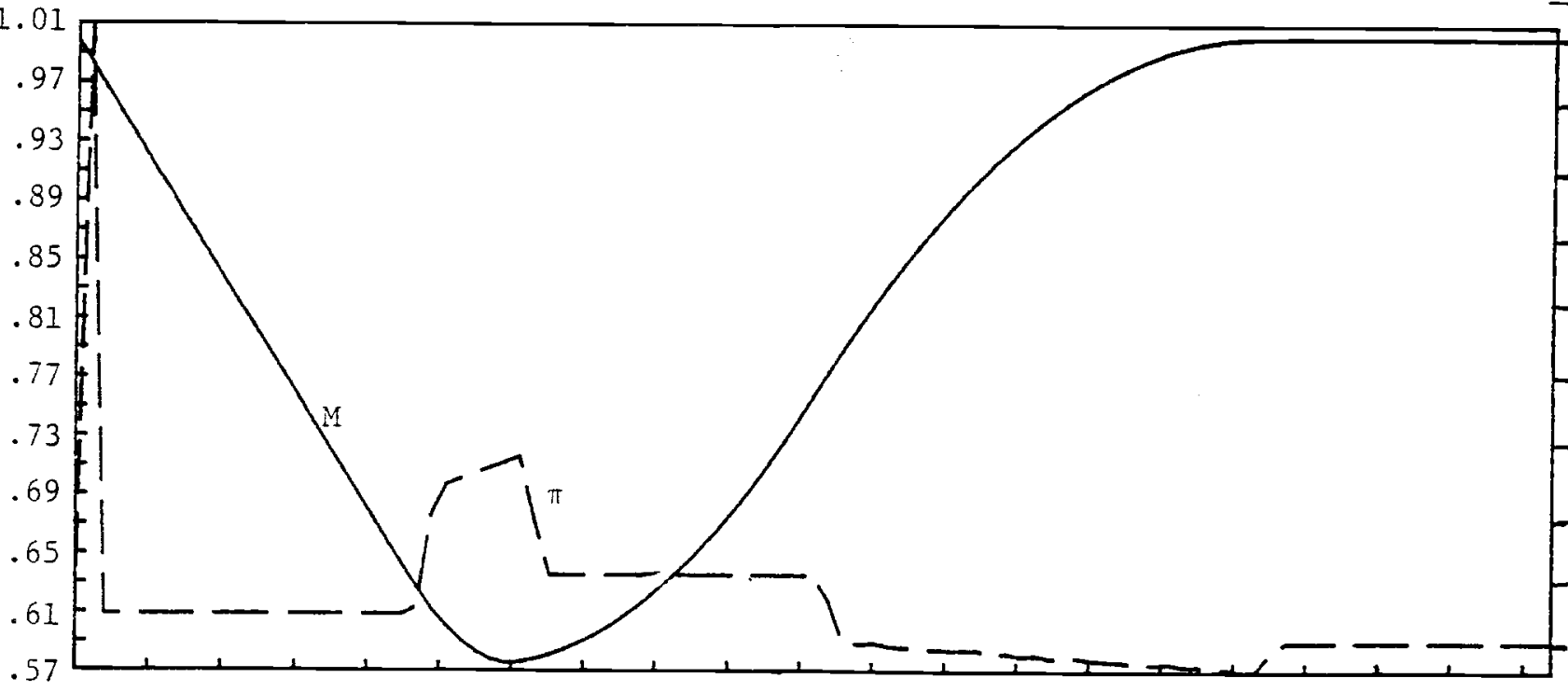

Inflation

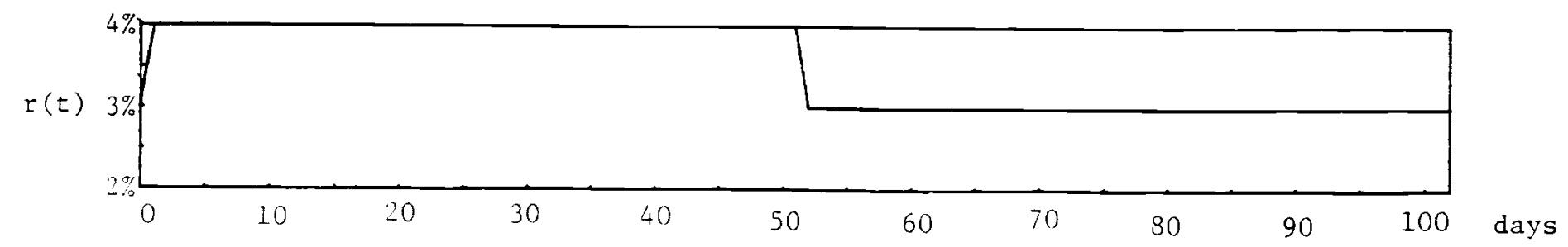


Figure 5.5

Response to Aigh Ereguercy Rate Poidc: : $\boldsymbol{\omega}=\mathbf{2 . 5}$

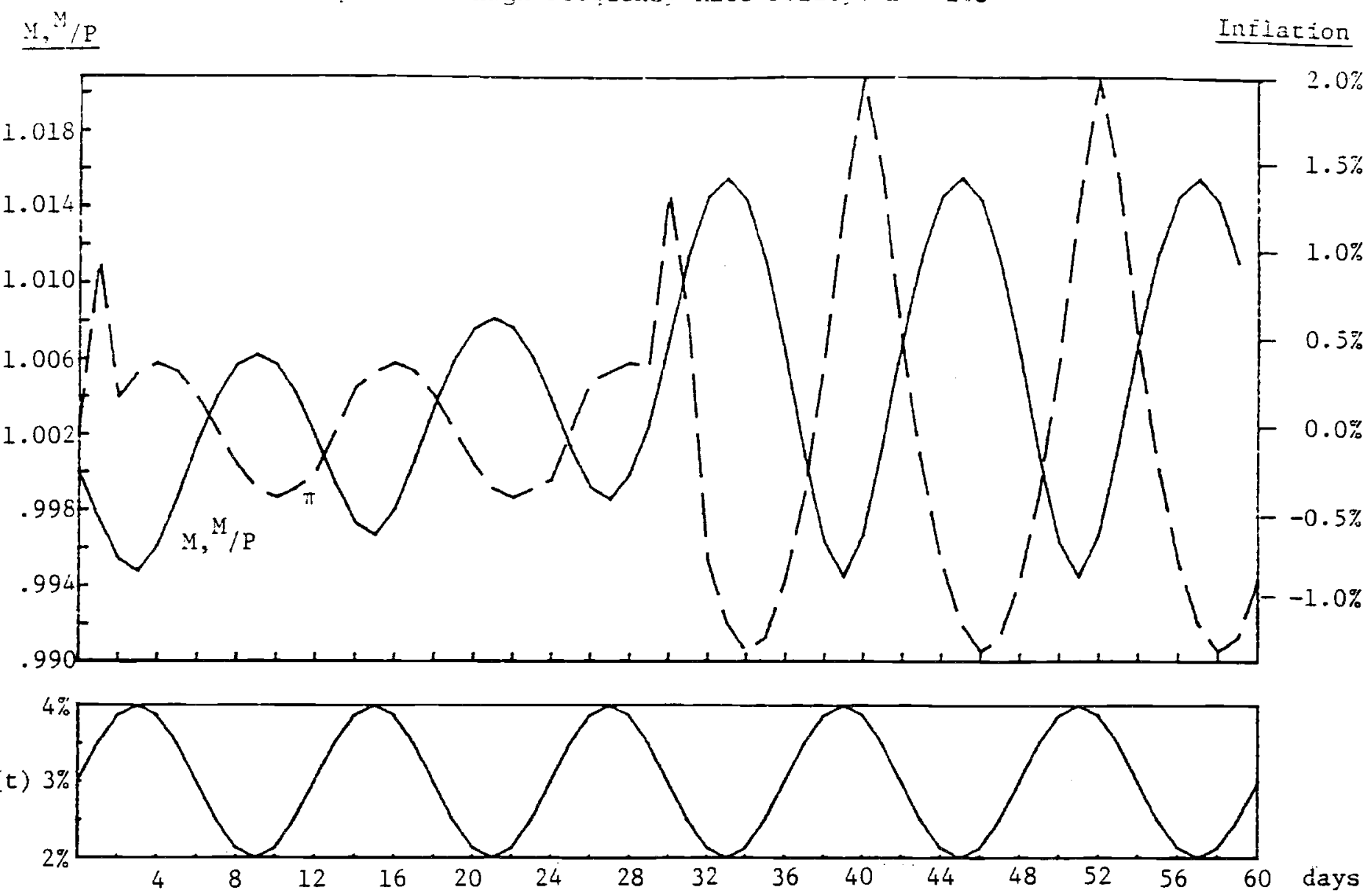

Figure 5.6

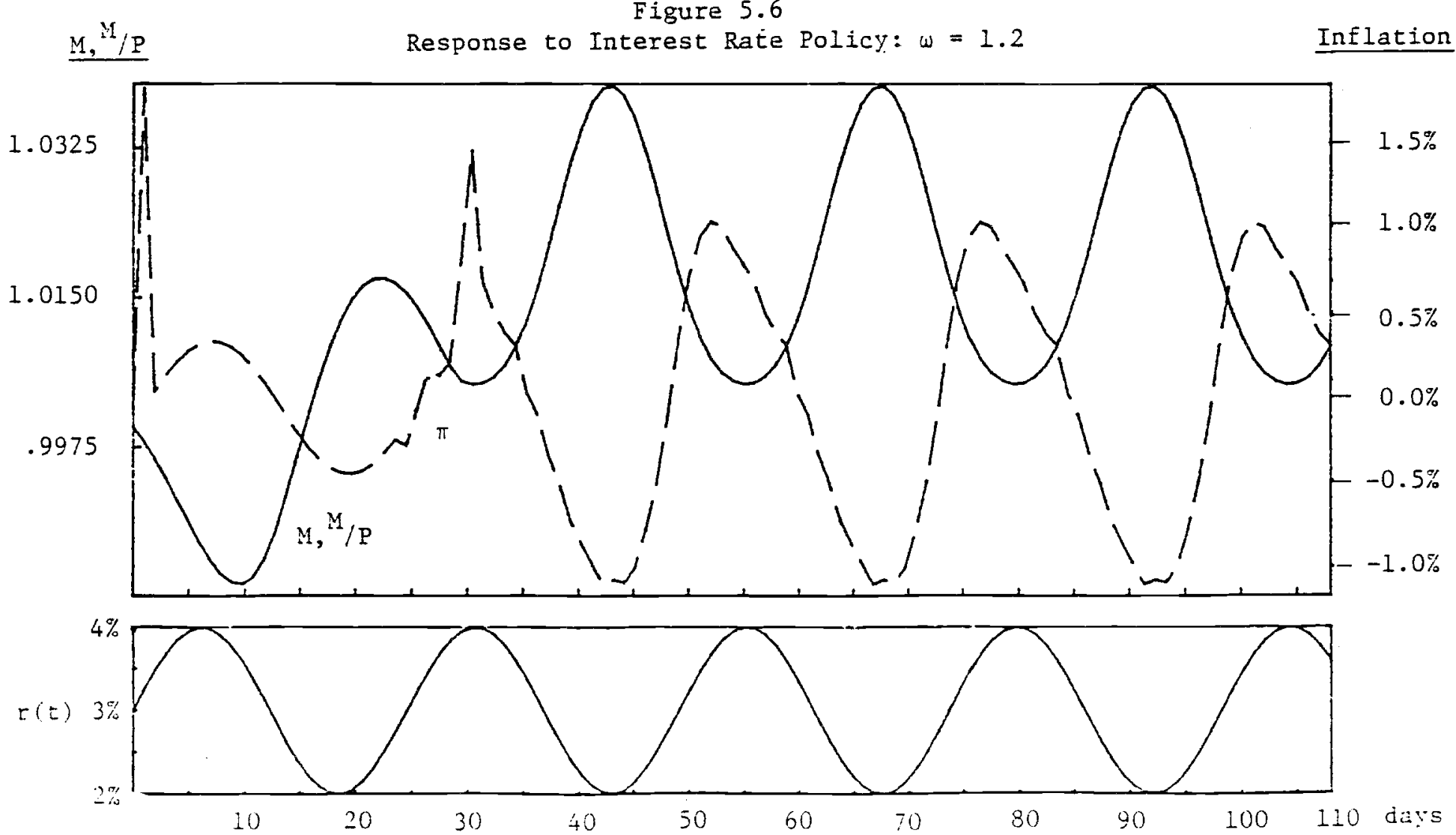



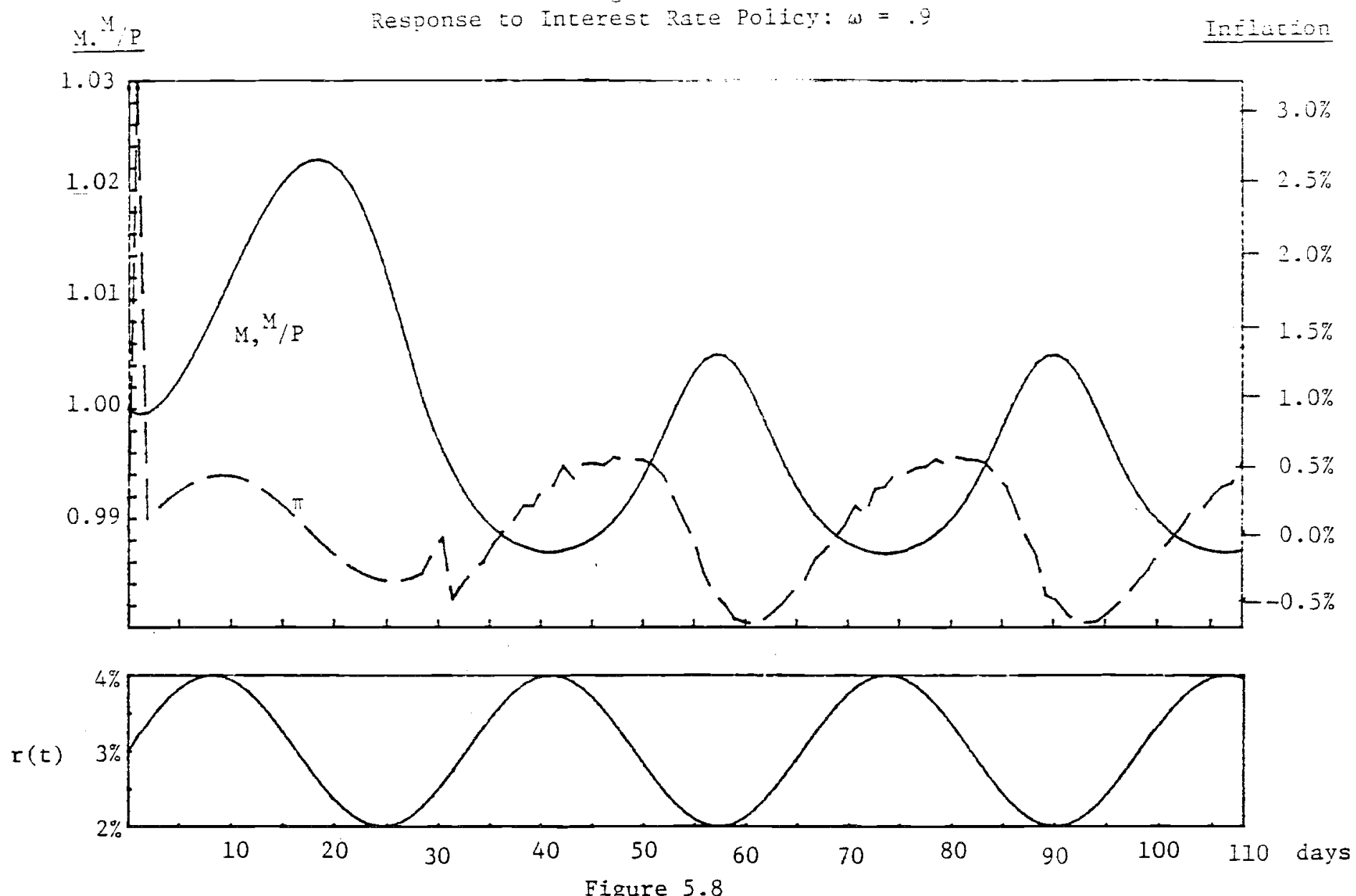

$M, M / P$

Response to Interest Rate Policy: Low Frequency $\omega=.25$

Infilation
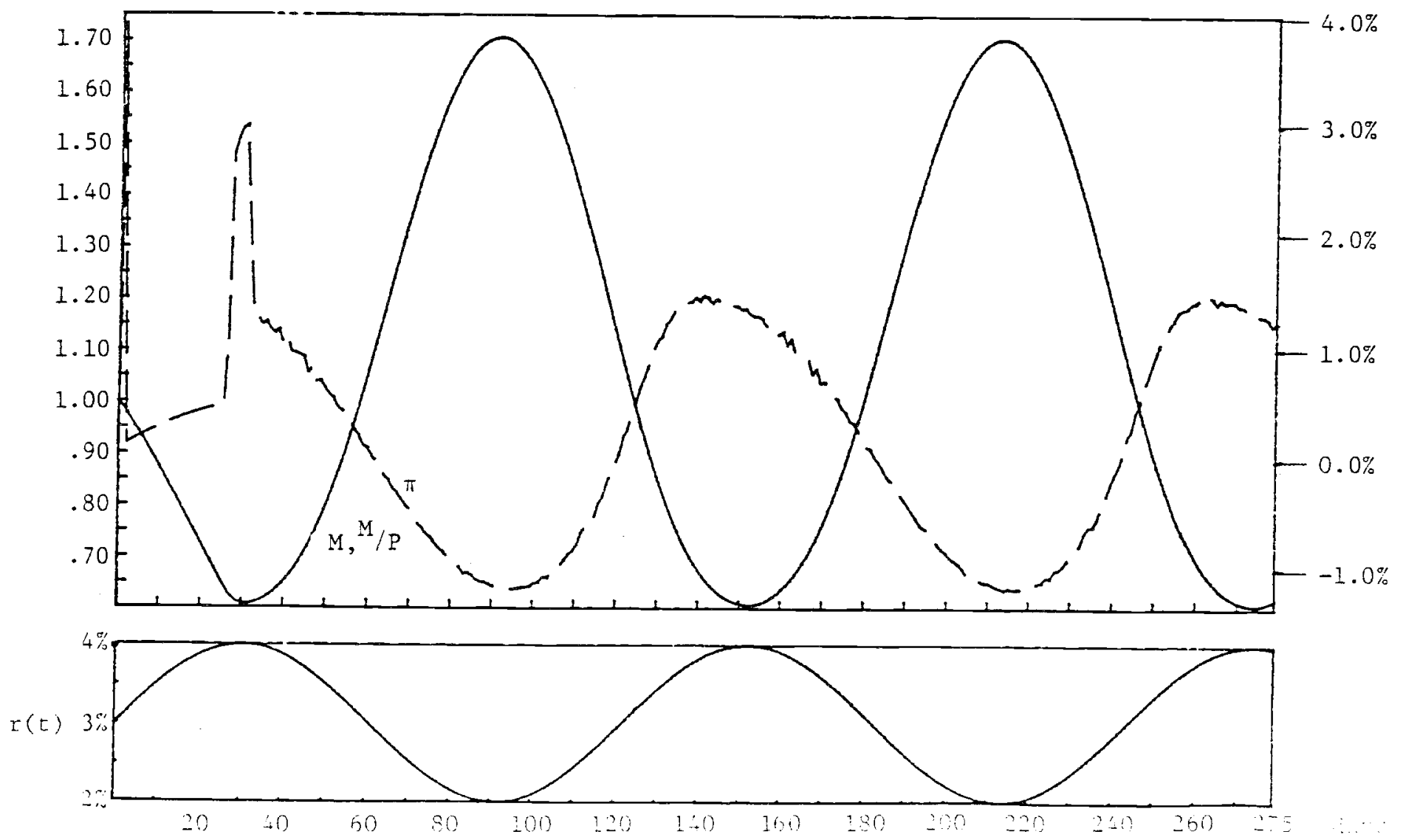
Elgue 5.9
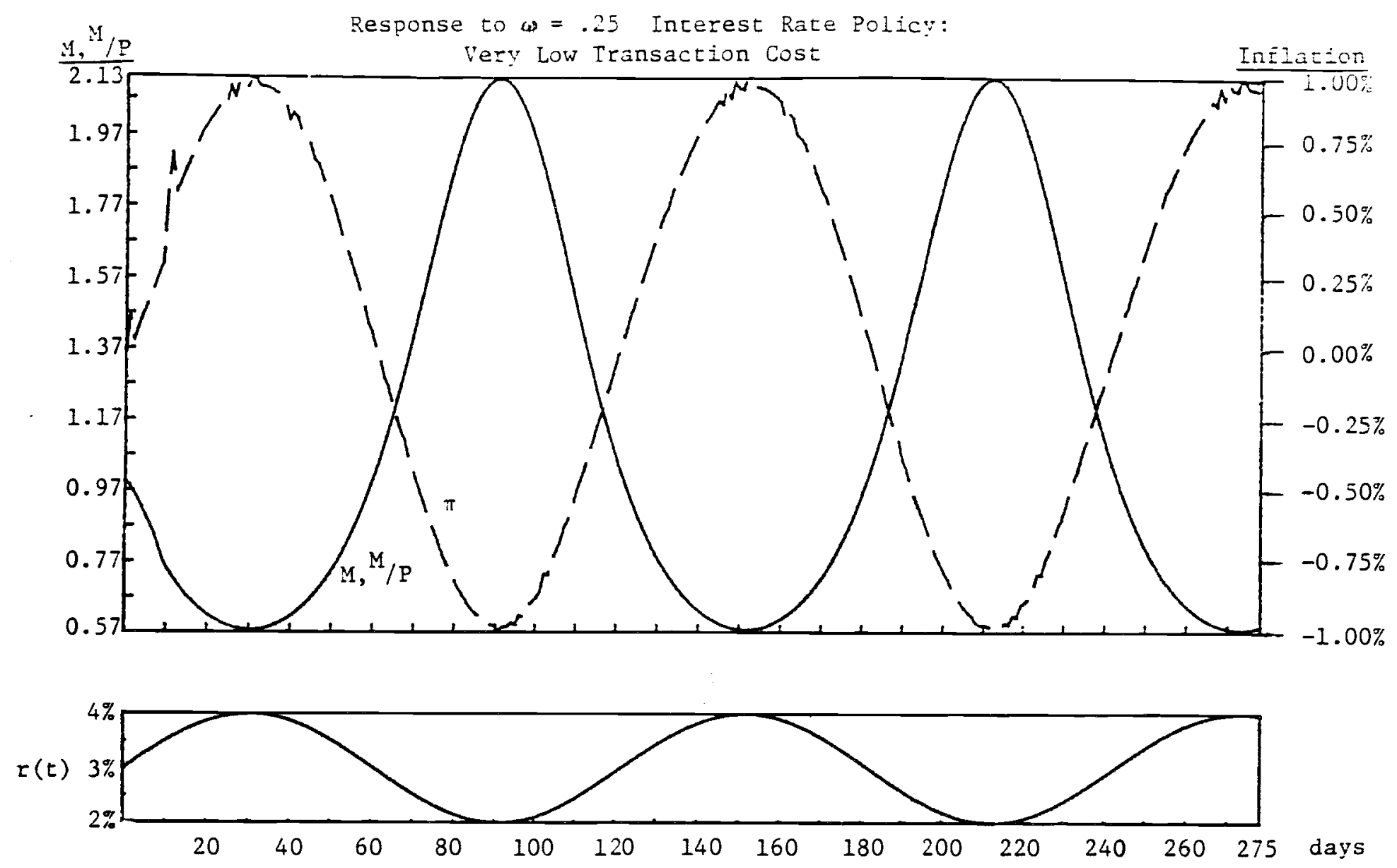

Figure 5.10
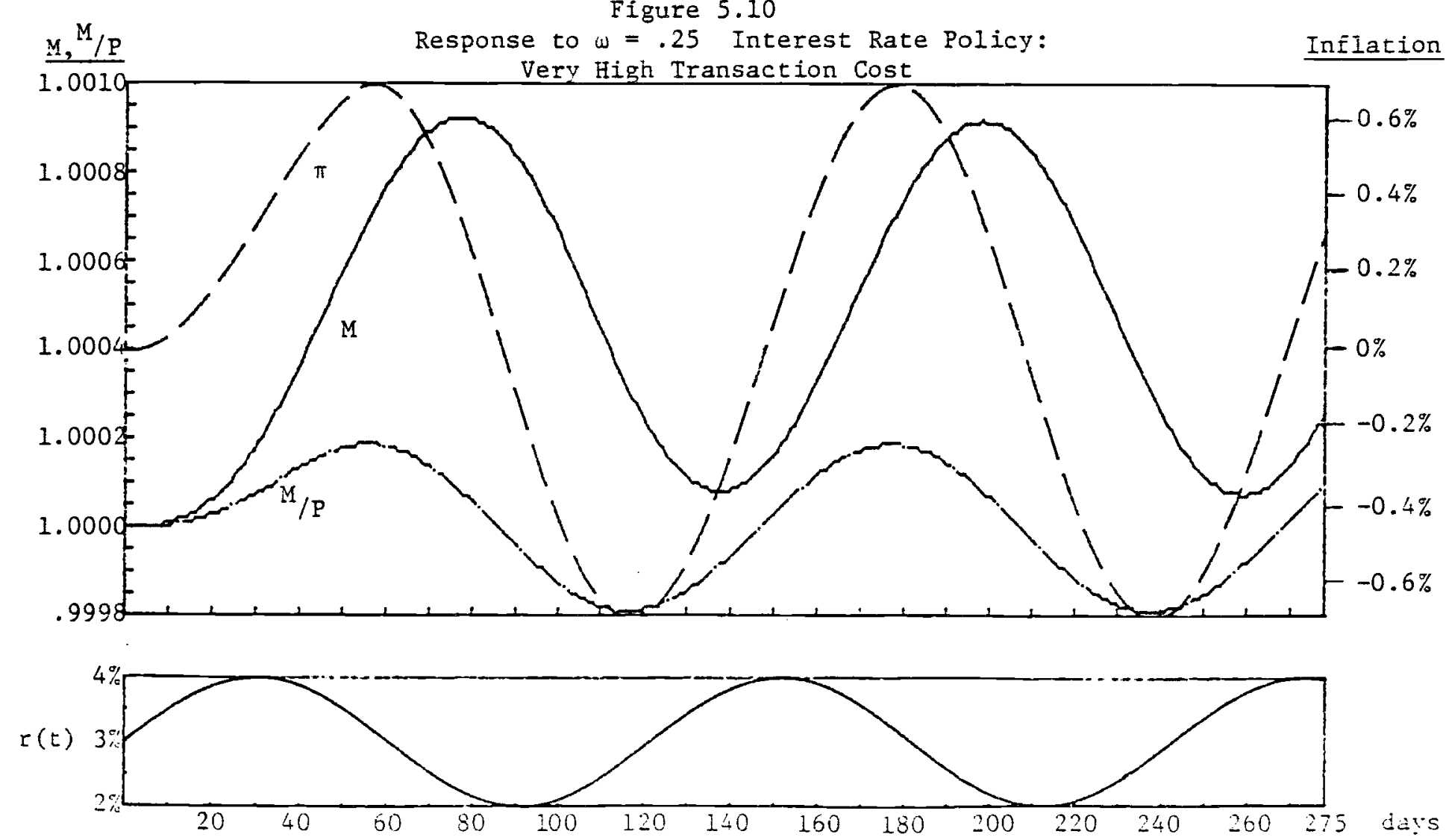
6. CONCLUSIONS

We have developed a simple model of money demand based upon a fixed payment period and a proportional transactions cost of converting bonds into money. The model is useful for analyzing the short run dynamics associated with various anticipated and unanticipated monetary policies. A crucial feature of the model is that there is an endogenous money holding period. Hence, though consumers do not find it optimal to cause a jump in their stock of eash balances when a new monetary policy is announced, they do adjust the rate at which they exhaust their cash (i.e., their spending flow). Hence, as in earlier work there is a liquidity effect associated with the transactions cost of converting between money and bonds, but the size of the liquidity effect is endogenous here.

The two classes of monetary policies analyzed here are price level policies and interest rate policies. Price level policies are monetary polices which in general equilibrium keep the nominal rate constant, but change the long run price level. We have shown that the money supply must rise gradualiy to its new steady state level if the price level is to be raised without causing nominal interest rates to fall. After one payment period the money supply has risen by $g \%$ if the price level policy involves an increase in the price level of $8 \%$.

When interest rate policies are analyzed, it becomes clear that aggregate money demand at time $t$ depends on the path of interest rates, not just the instantaneous interest rate at time $t$. This is because the aggregate money holding at time $t$ is composed of the money holdings of various consumers, each of whom has a different but overlapping holding period. The staggering of money holding periods is a necessary conditon for 
general equilibrium; general equilibrium requires that some consumers must be incrementing their cash when other consumers are decrementing their cash via spending. (If all consumers decrement their cash at the same time, then where does the money go to?) That is, general equilibrium requires that not all consumers act in an identical manner. 1 '

Some results of our analysis which highlight the above point include the fact that high frequency movements of the interest rate cause a much smaller change in money demand than low frequency movements, since it is the integral of the interest rate over a holding period which determines money demand. Further, at high frequencies, the rate of inflation is not the difference between the nominal interest rate and the rate of time preference. This is because different consumers face different relevant paths of interest rates when the interest rate oscillates within the length of a pay period. Our theoretical results are consistent with the empirical relationships presented in Cochraine (1985) that there is a negative correlation between interest rate movements and money supply movements at frequencies of about 4 weeks. He also finds that higher frequency movements produce an effect too small to measure, and very low frequency movements produce a positive correlation between money supply changes and interest rates; all of which is consistent with the results in Section 5 of this paper. A model which distinguishes between low frequency and high frequency interest rate movements is also necessary to explain the money supply announcement effects (documented in e.g., Cornell (1983)), though clearly a stochastic version of our model must be developed for this purpose.

In contrast to previous work on monetary dynamics with overlapping pay periods and exozenous money holding periods (where the interest rate elasticity of money demand is almost zero), the aggregate demand for money 
here is very interest rate elastic. $\stackrel{2}{\prime}^{\prime}$ In those earlier models the low interest rate elasticity implied that a very small open market operation, say of about $5 \%$ per year is sufficient to drive the nominal interest rate to zero. The monetary velocity, and the aggregate interest rate elasticity observed in the US is probably generated by a combination of the two models. That is, the consumers in the model developed here with high elasticities represent firms in our economy for whom the fixed transactions cost of converting between bonds and cash may be negligible, but for whom the proportional transactions cost is important. For consumers in our economy the fixed and proportional transactions costs are much higher, and it is probably a satisfactory approximation to take their money holding period as fixed over a large range of interest rates. ${ }^{3 /}$ Hence aggregate money demand probably responds to shocks as if it is composed of a convex combination of consumers with a small proportional transactions cost, and another group of consumers with a sufficiently large proportional transactions cost that their money holding period is fixed.

The model clearly needs to be extended to deal with a fixed transactions cost as well as a proportional cost. The non-convexities associated with a fixed cost makes this difficult except for very simple interest rate policies. Another problem with the model is that it is not explicitly stochastic, so that it is impossible to understand the effects of high frequency innovations to the money supply. The proportional transactions cost model may be far simpler to develop in a stochastic framework than the fixed cost model. 


\title{
FOOTNOTES FOR SECTION 1
}

\begin{abstract}
* Department of Economics, University of Chicago. I am grateful to Jerry Fusselman and Narayana Kocherlakota for helpful comments. The computer simulations were generated by Narayana Kocherlakota and Chi Ki Chaing.

1'see Jovanovic (1982) for an analysis of the steady state of an economy where there is a cash in advance constraint and a fixed cost of converting between capital and money. See Leach (1982) for an analysis of the steady state of an economy where there is a proportional transactions cost, but each consumer spends out of money for only a single period in his life.
\end{abstract}

\section{FOOTNOTES FOR SECTION 2}

1'The proportional cost model has been chosen because of its tractability. I prefer a model without exogenously determined paydates, where a consumer can withdraw any sum of money for a fixed transactions cost. I have analyzed the steady states of such a model in Grossman [1982], and it is quite similar to the steady states of the proportional transactions cost model. However, the non-convexities inherent in the fixed cost model make the dynamics intractible except for the simplest sorts of interest rate policies.

2' This is the obvious benefit from using proportional rather than fixed transactions costs. 


\begin{abstract}
$\underline{3}^{\prime}$ In $(2.15)$ and $(2.16)$ if $n \geq 1$ and if $T(z+n h)>z+(n+1) h$ then $Y\left(t_{n}(z)\right) / k$ must be replaced by $Y(z+n n)$.
\end{abstract}

FOOTNOTES FOR SECTION 4

1 'Note from (2.18) that a rise in the price level, i.e., a fall in $q$, causes $t_{0}(x)$ to fall. Hence $t_{0}^{*}<t$, so that none of the people who have made a withdrawal in $(0, t)$ have yet exhausted their cash. If instead, $\alpha<0$, then the first integral on the RHS of (4.5) would be from $L$ to $t$, rather 0 to $t$. The argument given can be modified in an obvious manner in this case.

2'All the numerical simulations in this paper are solutions to a discrete time version of the model. In the discrete time version agents choose an integer number of periods over which to exhaust their cash. It is assumed that the new policy is announced at the end of period zero, so that consumers making a withdrawal at time zero can do so with perfect foresight about the path of prices and interest rates. The simulations reported in Figure 4.1 are based on a discretization of 1 period $=1 / 365$ of a year.

$\underline{3}^{\prime}$ From (4.9) it is clear that the jump in prices to the new steady state level is not instantaneous because $t_{0}(x)$ falls when $q$ falls. If $\beta=r$ then (2.18) can be used to compute:

$$
\frac{d \log t_{o}(x)}{d \log q}=\frac{1-e^{-\beta t_{0}(x)}}{B t_{0}(x)}=1
$$

so $t_{0}(x)$ is very sensitive to $q$. However $Y\left(t_{0}(x)\right)=e^{\beta t_{0}(x)}$ is not very sensitive to $q$ : 


$$
\frac{d \log \gamma\left(t_{0}(x)\right)}{d \log q}=\beta t_{0}(x) \frac{d \operatorname{dog} t_{0}(x)}{d \log q}=\beta t_{0}(x)
$$

which in the simulations is at most $(.03)(30 / 365)$. Thus spending will move very quickly to its new steady state value. It is interesting to note why the money supply does not also move very quickly to its new steady state value. From (4.8) the percentage change in the money held at time 0 by someone who has a paydate of $x$ is less than $1+\alpha$ by a factor:

$$
\frac{d \log e^{B t_{0}(x)}}{d \log q}\left[1-e^{-B t_{0}(x)}\right]=\left[1+B t_{0}(x)\right] \frac{d \log t_{0}(x)}{d \log q}=B t_{0}(x)+1
$$

Intuitively, the fact that spending will move proportionally with $q$ implies that money holdings will change much less than proportionally because $t_{0}(x)$ falls a lot when $q$ rises.

\section{FOOTNOTES FOR SECTION 5}

1 'The derivation in $(5.4)$ refers to the derivative from the right, i.e., from $t>0$.

2/Unless stated otherwise, all the plots in section 5 are for the discretized version of the model with 1 period $\equiv 1 / 365$ years. The proportional transaction cost is chosen to generate a steady state holding period of 30 days at an interest rate of $3 \%$. The pay period is set equal to 50 days.

$\underline{3}^{\prime}$ More precisely the Figures are drawn using the function $r(t)=$ $.03+.01 \mathrm{sin} \frac{2 \mathrm{~T} \omega t}{30}$ to give the annual interest rate at day $t$. Further, the plots of the inflation rate were generated by using a discretization of 4 
periods per day and then using the average price per day to compute the inflation rate. This is because there was too much numerical noise in inflation calculations from period to period.

\section{FOOTNOTES FOR SECTION 6}

1'Thus our model snould be distinguished from models which use one period (lower cash in advance constraints such as Grandmont and Younes (1972)). In such models all consumers decrement their cash during a period, and markets only clear at the end of each period.

?' See Lucas and Stokey (1983) for a cash in advance constraint model where the demand for money depends on the nominal rate of interest, but in which the money holding period is exogenous.

3' A clearer way of stating this is that consumers and firms face the same transactions cost schedule, but firms are operating at much higher levels of cash on the same schedule. The schedule involves a fixed cost plus a U shaped proportional cost.

\section{REFERENCES}

Cochrane, J. "The Return of the Liquidity Effect," in unpublished $P A$. D. dissertation, Department of Economics, University of Califor $\mathrm{nia}$, Berkeley.

Cornell, B. "The Money Supply Announcements Puzzle: Review and Interpretations," American Economic Review, 73, 644-657, Sept. 1983. 
Grandmont, J.M. and Y. Younes. "On the Role of Money and the Existence of a Monetary Equilibrium," Review of Economic Studies, Vol. 39, 355-72, July 1972 .

Grossman, S. and L. Weiss. "A Transactions Based Model of the Monetary Transmission Mechanism," American Economic Review, Vol. 73, No. 5 , Dec. $1983,871-80$.

Grossman, S. "A Transactions Based Model of the Monetary Transmis $\mathrm{S}$ i on Mechanism Part 2," National Bureau of Economic Res $\underline{\text { eq }} \underline{\text { r }} \underline{\text { h }}$, Working Paper No. 973, Sept. 1982.

Grossman, S. "Class Notes on the Transactions Demand for Money," Unpublished mimeo, Dec. 1982.

Leach, J. "Monetary Adjustment in an Intergenerational Economy," unpublished mimeo, Department of Economics, McMaster University, March 1982.

Lucas, R. and N. Stokey. "Optimal Fiscal and Monetary Policy in an Economy Without Capital," Journal of Monetary Economics, 12:55- 93 (1983).

Rotemberg, J. "A Monetary Equilibrium Model with Transactions C os t s," Journal of Political Economy, Vol.92, No. 1, Feb. 1984, 40 58. 
Sargent, $T$. and $N$. Wallace. "Rational Expectations, the Optimal Monetary Instrument, and the Optimal Money Supply Rule," Journal of Political Economy Vol. 83, No. 2, 241-254, April 1975.

Sidrauski, M. "Inflation and Economic Growth," Journal of Political Economy, Dec. $1967,75,798-810$. 


\section{Appendix A}

\section{A1 Characteristics of Optimal Money Exhaustion Times}

Assume $\left.u^{\prime}(0)=\infty, u^{\prime}\right\rangle 0, u^{\prime \prime}\langle 0, r(t)\rangle 0, P(t)$ has at most a finite number of discontinuities in any finite interval of time. If $P(t)>0, k>$ 1, then there exists multipliers $q>0$ for the wealth constraint (2.5a) and $\lambda \geq 0$ for $(2.50)$ such that the optimal $c(t) \geq 0, D_{0} \geq 0$ and $t_{n}$ satisfy:

(A1) $e^{-\beta y} u^{\prime}(c(y))=\frac{k P(y) q}{Y(y)}$ for $t_{n} \leq y<z+(n+1) n, n=0,1,2,3 \ldots$ :

$$
e^{-B y} u^{\prime}(c(y))=\frac{P(y) q}{Y(z+n h)} \text { for } z+n h \leqslant y<t_{n}, n=1,2,3 \ldots ;
$$

(A3) If $t_{n}<z+(n+1) n$ then $\frac{Y\left(t_{n}\right)}{Y(z+n h)}=k$, for $n=1,2,3 \ldots$;

(A4) If $M_{0}-D_{0}>\int_{0}^{z+h} P(t) c(t) d t$, then:

$$
\begin{aligned}
& \text { (A4a) } u^{\prime}(c(y)) e^{-B y}=q \frac{P(y)}{Y(z+h)} \text { for } y \varepsilon[0, z+h] \\
& \text { (A4b) } \frac{1}{k} \leq \frac{1}{Y(z+h)} \text { and } D_{0}\left[\frac{1}{Y(z+h)}-\frac{1}{k}\right]=0 \text {. }
\end{aligned}
$$

(A5) If $M_{0}-D_{0} \leqq \int_{0}^{2+h} P(t) c(t) d t$, then:

$$
\begin{aligned}
\text { (A5a) } \gamma\left(t_{0}\right) \lambda & \leq q k \text { and }\left[q k-Y\left(t_{0}\right) \lambda\right]\left[z+h-t_{0}\right]=0 \text { if } t_{0}>0 ; \lambda \geq q k \\
& \text { if } t_{0}=0 ;
\end{aligned}
$$


$(A 5 b) u^{\prime}(c(y)) e^{-B y}=\lambda P(y)$ for $y \varepsilon\left[0, t_{0}\right)$;

$(A 5 c) \lambda \geq q / k$ and $D_{0}[\lambda-q / k]=0$;

(A5d) If there is equality in (A5) then $\lambda \geq q / Y(z+h)$;

The deriviation of the above inequalities is standard. Note that (A3) is derived from noting that a small increase in $t_{n}$ yields net benefit $q\left[\frac{k P\left(t_{n}^{+}\right) c\left(t_{n}^{+}\right)}{\gamma\left(t_{n}\right)}-\frac{P\left(t_{n}^{+}\right) c\left(t_{n}^{+}\right)}{\gamma(z+n h)}\right]$, and a small decrease in $t_{n}$ yields the same expression except that $t_{n}^{+}$is replaced by $t_{n}^{-}$. Hence (A3) holds even if $P(t)$ jumps at $t=t_{n}$. Note that (A5d) holds because when (A5) is an equality, i.e., $t_{0}=z+h$, it is always possible to reduce consumption a little at $t<z+h$, and hold the money for spending at $t_{0}=(z+h)_{+}$. The net benefit of such a decrement in spending before $t=z+h$ is $q / \gamma(z+h)-\lambda$, and this leads to (A5d).

The analysis of the initial exhaust time $t_{0}$ is complicated by the fact that the consumer may choose to make a deposit at time 0 , or to not exhaust his initial money holdings. The following theorem characterizes the optimal choice of his initial exhaustion policy. Let $F(x, y) \equiv \int_{0}^{x} P(t) c(t, y) d t$, where $c(t, y)$ is as defined in $(2.11)$.

\section{Theorem A1}

Let $q>0$ be given and $M_{0}>0$, then: Case (a) if $Y(z+h)>k$, then (A5) holds. In addition, if Case (a1) $F(z+h, q k / Y(z+h))<M_{0}$ and $F(z+h, q / k) \geq M_{0}$, 
then $t_{0}=z+h$ and $D_{0}=0$, and $\lambda$ is the solution to

(A6) $\quad F(z+h, \lambda)=M_{0}$;

Case (a2) if $F(z+h, q k / Y(z+h))<M_{0}$ and $F(z+h, q / k)<M_{0}$

and if $\gamma(z+h) \leq k^{2}$

then $t_{0}=z+h$ and $D_{0}=M_{0}-F(z+h, q / k)$ and $\lambda=q / k$;

if $\gamma(z+h)>k^{2}$ then $t_{0}$ is given by the solution to

(A7) $\quad r\left(t_{0}\right)=k^{2}$, and

(A8) $\quad \lambda=q k / \gamma\left(t_{0}\right)$, and

(A9) $D_{0}=M_{0}-F\left(t_{0}, q k / Y\left(t_{0}\right)\right)$;

Case (a3) If $F(z+h, q k / Y(z+h)) \geq M_{0}$, then

let $t^{*}$ solve

(A10) $F\left(t^{*}, q k / Y\left(t^{*}\right)\right)=M_{0}$,

and let

(A11) $\bar{\lambda}=q k / r\left(t^{*}\right)$.

If $\bar{\lambda}>q / k$ then $D_{0}=0, t_{0}=t^{*}$ and $\lambda=\bar{\lambda}$

If $\bar{\lambda} \leq q / k$ then $t_{0}, \lambda$, and $D_{0}$ are given by $(A 7)-(A 9)$.

If :

Case (b) $\quad Y(z+h) \leq k$, then it is impossible for $D_{0}>0$ and $t_{0} \varepsilon(0, z+h)$;

Case (b1) In addition if $F(z+h, q k / \gamma(z+h))<M_{0}$, then

consider the $\lambda^{*}$ which solves $(A \sigma)$. If $\lambda^{*}<q / Y(z+h)$ then $t_{0}=$ $z+h, c(t)$ is given by $(A 4 a)$ and $D_{0}[k-\gamma(z+h)]=0$. If $\lambda^{*} \geq$ $q / \gamma(z+h)$, then $c(t)$ is given by $(A 5 b), t_{0}=z+h$ and $D_{0}[k-$ $\gamma(z+h)]=0$.

Case (b2) In addition if $F(z+h, q k / Y(z+h)) \geqslant M_{0}$ then (A5) holds, and $t_{0}=t^{*}$, where $t^{*}$ is given by $(A 10)$, and $\lambda$ $=\hat{\lambda}$ as defined in $(A 11)$, and $D_{0}=0$. 
Proof

Note that $F(x, y)$ is increasing in $x$ and decreasing in $y$.

Case (a) From (A4b) we are sure that (A5) must hold.

Case (a)

The inequalities involving $F(\cdot)$ imply that $k^{2}>r(z+h)$. If $t_{0} \varepsilon$ $[0, z+h)$ then $F\left(z+h, q k / \gamma(z+h)<M_{0}\right.$ implies that $D_{0}>0$. Thus using (A5a) and (A5C) $k^{2} \leq Y\left(t_{0}\right)$ which is impossible, since $Y(\cdot)$ is nondecreasing. Since $t_{0}=z+h$, if $D_{0}>0$, then ( $A 5 c$ ) implies that $F(z+h, q / k)=M_{0}-D_{0}$ which contradicts $F(z+h, q / k) \geq M_{0}$.

Case (a2)

Note that for $t_{0} \varepsilon(0, z+h)$ and $D_{0}>0,(A 5 a)$ and $(A 5 c)$ imply that (A7) and $(A \dot{8})$ must hold. Hence if $Y(z+h) \leq k^{2}$ we have $t_{0}=z+h$ and $D_{0}=M_{0}$ - $F(z+h), q / k$ ) and $\lambda=q / k$ as the only solution to (A5) (recall that $\lambda$ $\leq q k / Y(z+h)$ since this inequality is equivalent to $Y(z+h) \leq k^{2}$ when $\lambda$ $=q / k)$. If $\gamma(z+h)>k^{2}$, then there is a $t_{0} \varepsilon(0, z+h)$ such that (A7) holds.

Case (a3)

Here there is exhaustion at a $t_{0} \varepsilon(0, z+h)$. If (A10) holds and $\bar{\lambda}$ in (A11) satisfies $\vec{\lambda}>q / k$, then we must have $D_{0}=0$ by (A5C). However if $\bar{\lambda}<q / k$, then we must have $D_{0}>0$, so the solution must instead be given by $(A 7)-(A 9)$. Note that $\bar{\lambda} \leq q / k$ implies $\gamma\left(t^{*}\right) \geq k^{2}$ so there will be a solution to (A8).

Case (b)

Here we must have $Y(z+h)<k^{2}$ so there is no solution to (A5a) and (A5C) with both as equalities. Thus $D_{0}>0$ implies $t_{0}=z+h$ and that (A5) must be an equality if it holds at all. 
Case (bl)

If $t_{0} \varepsilon(0, z+h)$ then $D_{0}=0$ and consumption would be zoverned by the $\lambda$ such that $\lambda=q k / Y\left(t_{0}\right)$ and $F\left(t_{0}, q k / Y\left(t_{0}\right)\right)=M_{0}$. $3 u t$ $F\left(t_{0}, q k / Y\left(t_{0}\right)\right)<F(z+h, k q / Y(z+h))$, which contradicts $F(z+h, q k / Y(z+h))$ $\left\langle M_{0}\right.$. Hence $t_{0}=z+h$, since $t_{0}=0$ implies $\left.D_{0}=M_{0}\right\rangle 0$ and (A5a) contradicts $(A 5 C)$. Note that $t_{0}=z+h$ means that if (A5) holds at all then it must hold as an equality. Further if (i) $\gamma(z+h)<k,(A 5)$ is impossible since $D_{0}>0$ implies $\lambda=q / k$ which contradicts ( $A 5 d$ ), and $D_{0}=0 \quad t_{0}=z+h$ implies that $\lambda=\lambda^{*}$ and $\lambda^{*}<q / \gamma(z+h)$ contradicts (A5d); while if (ii) $Y(z+h)=k$, it is impossible for (A5) to hold with $\lambda\left\langle q / k\right.$ by (A5d), while $\lambda>q / k$ would imply $D_{0}=0$ and thus $\lambda=$ $\lambda^{*}$ which contradicts $\lambda^{*}<q / \gamma(z+h)$ and $k=\gamma(z+h)$. Thus the optimal solution involves $\lambda=q / k=q / Y(z+h)$ and $D_{0}=M_{0}-F(z+h, q / k)$. It is also optimal to be in case (A4) and have $\left.D_{0}<M_{0}-F(z+h), q / Y(z+h)\right)$ when $k=Y(z+h)$; of course $(A 4 a)$ and (A5b) coincide in that case.

If $\lambda^{*} \geq q / Y(z+h)$, then $F(z+h, q / Y(z+h))>M_{0}$ so case (A4) is impossible. Hence (A5) holds with $\lambda=\lambda^{*}$.

Case (b2)

Note that $F(z+h, q / Y(z+h))>M_{0}$, since $F\left(z+h, q k / Y(z+h) \geq M_{0}\right.$, hence we cannot be in case (A 4$)$. Under the hypothesis of Case (b2) $t^{*} \leq z+h$. Further we cannot have $D_{0}>0$ since, (i) $t_{0}$ interior is ruled out in Case (b), and (ii) $t_{0}=z+h$ is ruled out by the fact that $Y(z+h) \leq k$ and $Y(z+h) \lambda \leqq q k$ imply $F(z+h, \lambda)>M_{0}-D_{0}$ which contradicts (A5) holding as an equality. Hence $D_{0}=0$. 
APPENDIX B

by

Narayana Kocherlakota

In this appendix, we will show that under some mild assumptions, the only distribution of paydates compatible with steady state constant aggregate money demand is $\exists$ uniform one.

of major importance in making this claim is the fact that if transaction costs are positive, individuals always spend out of money for some discrete time period after their paydates. This allows us to establish the following restriction on individual money holdings. Define $M^{*}(x)$ to be the money holdings of an individual paid $x$ periods ago; this is welldefined since the economy is in steady state. If the individual buys goods using his stock of cash, then

(P1) There exists $b>0$ such that $M^{*} \cdot(x)<0$ for all $x \in(0, b]$,

Clearly, $M^{*} \cdot(x) \leq 0$ for all $x \in(0, h)$.

We will assume that the distribution of paydates has an associated density function $f$, which we will require to be positive-valued and continuous on the real line. The structure of the model further implies that $f$ is periodic with period $h$ and that $\int_{0}^{h} f(z) d z=1$. Mathematically, then, we want to show $f$ is constant if aggregate money demand: 


$$
M^{d}(t)=\int_{t-h}^{t} M^{*}(t-z) f(z) d z
$$

is constant over $t$. To do so, we need the following lemma.

Lemma B.1: Define:

$$
T \equiv\left\{t \in[0, h] \mid f(t)=\sup _{x \in[0, h]} f(x)\right\}
$$

If $f$ is not constant, then there exist $t^{*} \varepsilon T$ and $\delta>0$ such that $\left[t^{*}\right.$ $\delta, t^{*}$ ) intersected with $T$ is empty.

Proof: We know $T$ is not empty since $f$ is continuous; let $s \in T$. Define $r(a)=\inf \{x \mid x \in T$ and $x \geq a\}$ for $a \varepsilon[0, s]$. $T$ is closed, so $r(a) \varepsilon$ $T$. Suppose the lemma is false. Then $r(a)=a$, and $[0, s]$ is contained in $T$. However, by the periodicity of $f$, this implies $h \in T$. It follows that $[0, h]=T$, which contradicts the hypothesis that $f$ is not constant. We can use this lemma and (P1) to prove our result.

Theorem B.1: If

(1) $\int_{t \sim h}^{t} M^{*}(t-z) f(z) d z=\bar{M}$

for all $t$, then $f$ is constant.

Proof: Suppose $f$ is not constant. Then let $t^{*} \varepsilon[0, h]$ have the property described in Lemma B.1. Differentiating (1) at $t^{*}$ then gives: 
(2) $\left[M^{*}\left(0^{+}\right)-M^{*}\left(h^{-}\right)\right] f\left(t^{*}\right)+\int_{t^{*}-h^{*}}^{t^{*}} M^{*} \cdot\left(t^{*}-z\right) f(z) d z=0$

where $M^{*}\left(x^{+}\right)=\lim _{y+x} M^{*}(y)$ and $M^{*}\left(x^{-}\right)=\lim _{y \uparrow x} M^{*}(y)$. Solving for $f\left(t^{*}\right)$ in (2), we obtain:

(3) $f\left(t^{*}\right)=\frac{\int_{t^{*}-n}^{t^{*}} M^{*} \cdot\left(t^{*}-z\right) f(z) d z}{M^{*}\left(h^{*}\right)-M^{*}\left(0^{+}\right)}$

Using $(P 1)$ and the fact that there exists $\delta>0$ such that $f\left[t^{*}-\delta, t^{*}\right)<$ $f\left(t^{*}\right)$, we can derive:

(4) $f\left(t^{*}\right)<\frac{\int_{t^{*}-h}^{t^{*}} M^{*} \cdot\left(t^{*}-z\right) f\left(t^{*}\right) d z}{M^{*}\left(h^{-}\right)-M^{*}\left(0^{+}\right)}=f\left(t^{*}\right)$.

of course, this is a contradiction. Q.E.D. 